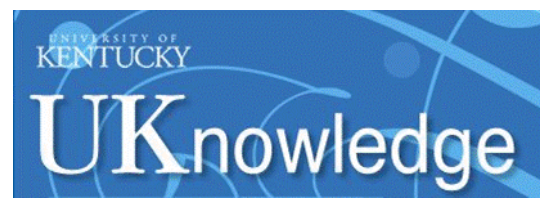

University of Kentucky

UKnowledge

\title{
Effect of Spalled Particles Thermal Degradation on a Hypersonic Flow Field Environment
}

\author{
Raghava S. C. Davuluri \\ University of Kentucky, raghava.sai.chaitanya@gmail.com \\ Huaibao Zhang \\ University of Kentucky, paulhuaizhang@gmail.com \\ Alexandre Martin \\ University of Kentucky, alexandre.martin@uky.edu
}

\begin{abstract}
Follow this and additional works at: https://uknowledge.uky.edu/me_facpub
Part of the Aerodynamics and Fluid Mechanics Commons, Fluid Dynamics Commons, Heat Transfer, Combustion Commons, Materials Chemistry Commons, Numerical Analysis and Computation Commons, Physical Chemistry Commons, Thermodynamics Commons, and the Transport Phenomena Commons Right click to open a feedback form in a new tab to let us know how this document benefits you.
\end{abstract}

\section{Repository Citation}

Davuluri, Raghava S. C.; Zhang, Huaibao; and Martin, Alexandre, "Effect of Spalled Particles Thermal Degradation on a Hypersonic Flow Field Environment" (2016). Mechanical Engineering Faculty Publications. 81.

https://uknowledge.uky.edu/me_facpub/81

This Conference Proceeding is brought to you for free and open access by the Mechanical Engineering at UKnowledge. It has been accepted for inclusion in Mechanical Engineering Faculty Publications by an authorized administrator of UKnowledge. For more information, please contact UKnowledge@lsv.uky.edu. 


\section{Effect of Spalled Particles Thermal Degradation on a Hypersonic Flow Field Environment}

Digital Object Identifier (DOI)

https://doi.org/10.2514/6.2016-0248

Notes/Citation Information

Published in 54th AIAA Aerospace Sciences Meeting.

Copyright ( 2016 by Raghava S.C. Davuluri, Huaibao Zhang, and Alexandre Martin.

The copyright holders have granted the permission for posting the article here. 


\title{
Effects of spalled particles thermal degradation on a hypersonic flow field environment
}

\author{
Raghava S.C. Davuluri, Huaibao Zhang ${ }^{\dagger}$ and Alexandre Martin \\ University of Kentucky, Lexington, KY, 40506, USA
}

\begin{abstract}
Two-way coupling is performed between a spallation code and a hypersonic aerothermodynamics CFD solver to evaluate the effect of spalled particles on the flow field. Time accurate solutions are computed in argon and air flow fields. A single particle simulations and multiple particles simulations are performed and studied. The results show that the carbon vapor released by spalled particles tend to change the composition of the flow field, particularly the upstream region of the shock.
\end{abstract}

\section{Introduction}

7 HERMAL protection system materials protect entry vehicles using through various physical phenomena.

1 For ablative material, one such phenomenon is surface recession, a process usually refer to as "ablation". As the material undergoes chemical transformation, mostly through oxidation, it has been observed that solid particles are also ejected from the surface, into the flow. This process is defined as "spallation". It is believed that the thermal, mechanical shear, or inner pressure stresses cause the ejection of the particles. The spalled particles are likely produced by disconnected fibers or chunks of material, and can also be formed by soot, a by-product of pyrolysis process.

The presence of spalled particles around the material is believed to affect the flow field, and thus the surface heating rates since the near surface chemistry is modified. Moreover, the particles ejection takes place before the material ablates, thereby escalating the heat rates at the surface and accelerating the material recession. The particle travels through a high temperature zone and re-radiate energy back to the surface as they heat-up, thus increasing the heat flux into the capsule. Through these phenomena, the spallation phenomenon affects the material directly. The particles tend to react chemically and physically with the species in the flow along their path, thus changing the chemical composition of the flow field, and hence altering the radiative heat flux.

Disagreements were found when experimentally measured heating rates and temperature profiles of Pioneer-Venus ${ }^{1}$ and Galileo Probe ${ }^{2,3,4}$ heat shields were compared with the theoretical analysis. The parameters were over-predicted at the stagnation point and under-predicted in the downstream region. Though the experimental results were re-evaluated by varying the extent of turbulence, no reasonable explanation was found. The results suggested that there were additional mechanisms that cause increase in radiation or turbulence in the downstream region, and spallation was believed to be one among them. Furthermore, when laser attenuation and emission spectroscopy measurements were performed by Raiche and Driver ${ }^{5}$ at NASA Ames Research Center, the results were unexpected. It was found that with an increase in heating rates, the optical attenuation increased for the PICA model. This was speculated to be due to the scattering, absorbing and reflecting nature of spalled particles. Also, the spectroscopy emissions in the inviscid region corresponded to black body at about $3800 \mathrm{~K}$, and was likely due to the presence of spalled particles. Spectroscopic measurements by Yoshinaka ${ }^{6}$ on ablating models in air flow field demonstrated the presence of CN emission spectra in the upstream region of the shock. Similar spectroscopic experiments by Kihara et. al. ${ }^{7}$ in the region ahead of the shock detected the presence of CN emission spectra in the nitrogen and air environments, and presence of $\mathrm{C}$ emission spectra in the argon environment. The most likely reason for the

\footnotetext{
*Graduate Student, Department of Mechanical Engineering, AIAA Student Member

${ }^{\dagger}$ Graduate Student, Department of Mechanical Engineering, AIAA Student Member

$¥$ Assistant Professor, Department of Mechanical Engineering; Associate Faculty at the Center for Computational Science, Senior Member AIAA. alexandre.martin@uky.edu
} 
presence of $\mathrm{CN}$ and $\mathrm{C}$ in the upstream region of the shock is due to spalled particles, as they are the only carbon source which can reach a distance that far from sample.

Based on above experimental observations, numerical models $8,9,7,10$ were developed to compute the dynamics of spalled particles. These models used the extracted flow field data to study the spallation behavior. Pace et. al. ${ }^{11}$ developed an Eulerian particle model of constant mass, and loosely coupled it to Computational Fluid Dynamics (CFD) code DPLR, ${ }^{12}$ to evaluate the impact of spalled particles on radiative heating.

Following these studies, a spallation model was recently developed ${ }^{13}$ to compute the properties of the particle. The code takes into account the reactivity of the particle with the flow field species. The code was one-way coupled, in the past, to the CFD module of Kentucky Aerodynamic and Thermal-response Solver $(\text { KATS })^{14}$ to evaluate the effect of flow field on the spalled particles. In order to assess the effectiveness of spalled particles on the flow field, a two-way coupling between the spallation model and KATS-CFD model was performed and is presented here. The coupling was performed for a single particle and multiple particles in argon and air environments.

\section{Methodology}

\section{II.A. Numerical Models}

\section{II.A.1. KATS - CFD}

The thermo-chemical non-equilibrium flow field in the continuum regime is computed using KATS-CFD, a laminar Navier-Stokes solver. ${ }^{15}$ The governing equation of the model is of form:

$$
\frac{\partial \mathbf{Q}}{\partial t}+\nabla \cdot\left(\mathcal{F}-\mathcal{F}_{\boldsymbol{d}}\right)=\mathbf{S}
$$

where $\mathbf{Q}$ is a vector of conservative variables, $\mathcal{F}$ and $\mathcal{F}_{\boldsymbol{d}}$ are convective and diffusive flux matrices, and $\mathbf{S}$ is the source term vector. The weak form of the governing equation is obtained by integrating Eq. 1 over a finite volume $V$ for an arbitrary mesh cell and is given by:

$$
\iiint_{V} \frac{\partial \mathbf{Q}}{\partial t} d V+\iint_{A}\left(\mathcal{F}-\mathcal{F}_{\boldsymbol{d}}\right) \cdot \mathbf{n} d A=\iiint_{V} \mathbf{S} d V
$$

where Gauss theorem is applied to the flux integral. Assuming uniform physical properties everywhere within the control volume, the left hand side term of the equation is integrated in time by employing first-order backward Euler method, and integration of the flux integral is performed by adding the fluxes across each surface. The final form of equation that is solved is

$$
\left[\frac{V}{\Delta t}\left(\frac{\partial \mathbf{Q}}{\partial \mathbf{P}}\right)^{n}-\left(\frac{\partial \mathbf{R}}{\partial \mathbf{P}}\right)^{n}\right] \Delta \mathbf{P}=\mathbf{R}^{n}
$$

where $\mathbf{P}$ is a vector of primitive variables, $\Delta t$ is the time step size, and $\mathbf{R}$ is residual vector which is expressed as:

$$
\mathbf{R} \equiv \sum_{j \in \text { cell }}\left(\mathcal{F}_{\boldsymbol{d}}-\mathcal{F}\right) \cdot \mathbf{n}_{j} A_{j}+V \mathbf{S}
$$

where $A$ and $\mathbf{n}$ are face area and face normal respectively. The vectors of conservative variables, primitive variables, and source terms are of form: 


$$
\mathbf{Q}=\left(\begin{array}{c}
\rho_{1} \\
\vdots \\
\rho_{n g s} \\
\rho_{g} u \\
\rho_{g} v \\
\rho_{g} w \\
\rho E \\
\rho E_{v e}
\end{array}\right), \quad \mathbf{P}=\left(\begin{array}{c}
\rho_{1} \\
\vdots \\
\rho_{n g s} \\
u \\
v \\
w \\
T \\
T_{v e}
\end{array}\right), \quad \mathbf{S}=\left(\begin{array}{c}
\dot{\omega}_{1} \\
\vdots \\
\dot{\omega}_{n g s} \\
0 \\
0 \\
0 \\
0 \\
\dot{\omega}_{v e}
\end{array}\right)
$$

where $\rho_{i}$ is the density of species $i,(u, v, w)$ are the components of bulk velocity, $E$ and $E_{v e}$ are the total energy and vibrational-electron-electronic energy per unit mass characterized by temperature $T$ and $T_{v e}$, respectively. $\dot{\omega}_{i}$ is mass production rate of species $i, \dot{\omega}_{v e}$ is the vibrational energy transfer rate between two different energy modes, subscripts from 1 to ngs represent the number of species, and subscript $g$ represents the gas mixture. The convective and diffusive flux matrices in Eq. 1 are given as:

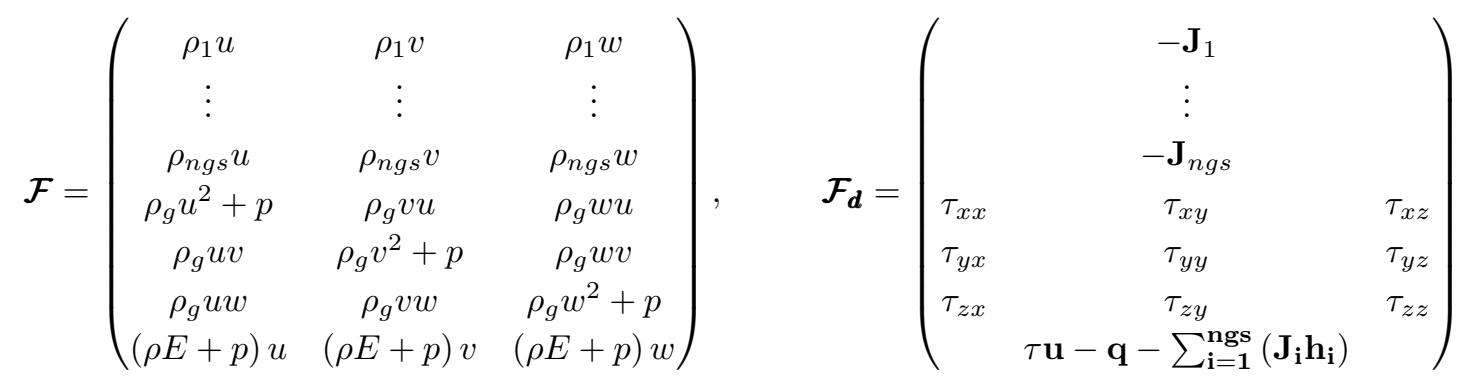

where $p$ is the total pressure, $\tau$ is viscous tensor, $\mathbf{J}_{\mathbf{i}}$ is the diffusive flux of species $i$, and $\mathbf{q}$ is the directional heat flux vector. The code employs second order spatial discretization and first order temporal integration.

\section{II.A.2. Spallation Model}

The model simulates the dynamics of a spalled particle by employing a Lagrangian formulation. ${ }^{16}$ The model also includes the chemical interaction of the particle with the flow field. The governing equation of the model is of form:

$$
\frac{\partial \mathbf{U}}{\partial t}=\mathbf{W}
$$

where $\mathbf{U}$ is the state vector and $\mathbf{W}$ is the source term vector. The elements of the vector are represented as:

$$
\mathbf{U}=\left(\begin{array}{c}
m_{p} \\
m_{p} u_{p} \\
m_{p} v_{p} \\
m_{p} w_{p} \\
m_{p} E_{p}
\end{array}\right), \quad \mathbf{W}=\left(\begin{array}{c}
\dot{m}_{\mathrm{C}} \\
F_{D_{x}} \\
F_{D_{y}} \\
F_{D_{z}} \\
\dot{q}_{c o n v}+p_{\text {drag }}-\dot{q}_{\text {rad }}+\dot{q}_{r x n}
\end{array}\right)
$$

where $m_{p}$ is the mass of the particle, $\left(u_{p}, v_{p}, w_{p}\right)$ are velocity components of the particle, $E_{p}$ is the total energy of the particle, $\dot{m}_{\mathrm{C}}$ is the mass source term, $\left(F_{D_{x}}, F_{D_{y}}, F_{D_{z}}\right)$ are components of drag force acting on the particle, and $\dot{q}_{c o n v}, \dot{q}_{r a d}, \dot{q}_{r x n}, p_{d r a g}$ are convective, radiative, reaction heat rates, and power drag. The particle surface reactions considered in this model are oxidation, nitridation, and sublimation. The reactions are irreversible in nature and are given in Table 1. The mass recession rates due to oxidation and nitridation are computed by employing parameters from Driver's chemistry model, ${ }^{17,18}$ whereas Knudsen-Langmuir 
Table 1. Surface chemistry model considered for Spallation model

\begin{tabular}{cc}
\hline \hline Type & Reactions \\
\hline Oxidation & $\mathrm{C}(\mathrm{s})+\mathrm{O} \longrightarrow \mathrm{CO}$ \\
Oxidation & $2 \mathrm{C}(\mathrm{s})+\mathrm{O}_{2} \longrightarrow 2 \mathrm{CO}$ \\
Nitridation & $\mathrm{C}(\mathrm{s})+\mathrm{N} \longrightarrow \mathrm{CN}$ \\
Sublimation & $\mathrm{C}(\mathrm{s}) \longrightarrow \mathrm{C}_{1}$ \\
Sublimation & $2 \mathrm{C}(\mathrm{s}) \longrightarrow \mathrm{C}_{2}$ \\
Sublimation & $3 \mathrm{C}(\mathrm{s}) \longrightarrow \mathrm{C}_{3}$ \\
\hline \hline
\end{tabular}

equation ${ }^{19}$ is used to calculate the recession rate due to sublimation. Hence, the final form of mass source term can be expressed as:

$$
\dot{m}_{\mathrm{C}}=-\dot{m}_{\mathrm{C} / \mathrm{CO}}-\dot{m}_{\mathrm{C} / \mathrm{CN}}-\dot{m}_{\mathrm{C} / \mathrm{C}_{1}, \mathrm{C}_{2}, \mathrm{C}_{3}}
$$

where $\dot{m}_{\mathrm{C} / i}$ denote the mass recession rates due to reaction producing species $i$.

\section{II.B. Two-way Coupling Method}

\section{II.B.1. Solution Technique}

Initially, a steady state solution is computed for the flow field environment by using KATS-CFD. The flow field parameters are used by the spallation model to calculate the dynamics of the particle. The two-way coupling is achieved by inserting the elements of source term vector $\mathbf{W}$ into the source term vector $\mathbf{S}$ of the CFD code. The coupling is performed according to the following:

\section{- Mass Coupling}

The products released from the surface reactions of the particle tend to effect the total composition of the flow field environment. The mass recession rates from spalled particle is inserted into CFD code as:

$$
\dot{\omega}_{i}=\dot{\omega}_{i}+\frac{\dot{m}_{\mathrm{C} / i}}{V} \quad\left(i=\mathrm{CO}, \mathrm{CN}, \mathrm{C}_{1}, \mathrm{C}_{2}, \mathrm{C}_{3}\right)
$$

where $V$ is the volume of the mesh cell in which the spalled particle is present. ${ }^{20}$ The mass coupling also accounts for the change in concentrations of oxygen (atomic and molecular) and atomic nitrogen responsible for the particle surface reactions, which is given as:

$$
\begin{gathered}
\dot{\omega}_{\mathrm{O}}=\dot{\omega}_{\mathrm{O}}-\left(\frac{M_{w \mathrm{O}}}{M_{w \mathrm{C}}}\right) \frac{\dot{m}_{\mathrm{C} / \mathrm{CO}}}{V} \\
\dot{\omega}_{\mathrm{N}}=\dot{\omega}_{\mathrm{N}}-\left(\frac{M_{w \mathrm{~N}}}{M_{w \mathrm{C}}}\right) \frac{\dot{m}_{\mathrm{C} / \mathrm{CN}}}{V} \\
\dot{\omega}_{\mathrm{O}_{2}}=\dot{\omega}_{\mathrm{O}_{2}}-0.5\left(\frac{M_{w \mathrm{O}_{2}}}{M_{w \mathrm{C}}}\right) \frac{\dot{m}_{\mathrm{C} / \mathrm{CO}}}{V}
\end{gathered}
$$

where $M_{w i}$ is the molar mass of species $i$.

\section{- Momentum Coupling}

The motion of the spalled particle is a result of drag force acting on it. Hence, momentum coupling deals with the reaction of drag force on the continuum regime. The elements of $\mathbf{S}$ corresponding to the momentum terms which are inserted from spallation model are:

$$
\dot{\omega}_{m o m, i}=-\frac{F_{D_{i}}}{V}
$$

where $i$ refers to the $x-, y$-, and $z$-directions. 


\section{- Energy Coupling}

The energy rate terms of spalled particle from the vector $\mathbf{W}$ which effect the flow field are $\dot{q}_{\text {conv }}, p_{\text {drag }}$, and $\dot{q}_{r x n}$. The convective heat rate $\left(\dot{q}_{c o n v}\right)$ accounts for the heat transfer rate between the flow field and spalled particle. The heat energy released/absorbed due to particle reactions per unit time $\left(\dot{q}_{r x n}\right)$ effect the temperature of the flow field. The work done by the particle to overcome the drag force $\left(p_{\text {drag }}\right)$ affects the kinetic energy of the flow field. Hence, the energy coupling is performed by inserting the energy rate terms from $\mathbf{W}$ into $\mathbf{S}$ as:

$$
\dot{\omega}_{t r}=-\frac{\dot{q}_{c o n v}+p_{d r a g}+\dot{q}_{r x n}}{V}
$$

It is assumed that the radiative heat rate from the particle effects the ablative material, and is less effective on the flow field. Hence, $\dot{q}_{\text {rad }}$ term is not considered in the energy coupling.

Starting from the initial converged CFD solution, KATS is used in a transient mode, and the spallation source terms are added to the cell centers as given by Eqs. 10 - 15 along the path of the particle. To maintain a time accurate solution, the Courant-Friedrichs-Lewy (CFL) number in the CFD code is kept under 1.

\section{II.B.2. Cell-center Locating Code}

The source vector $\mathbf{S}$ is computed at the cell centers of the mesh, whereas the spallation model provides results based on nodal properties. A new algorithm was developed to locate the center of the mesh cell in which the spalled particle is present. Using the algorithm, the source terms calculated by the spallation code are added to CFD code at center of the cell in which the particle is present. Figure 1 illustrates the trajectory of a $30 \mu \mathrm{m}$ particle ejected normally from the surface, $5 \mathrm{~mm}$ from the center axis, at an initial velocity of $90 \mathrm{~m} / \mathrm{s}$ in the air flow field. The cell centers computed by the new algorithm, denoted by red squares, are shown at three different locations with regards to the position of the particle.
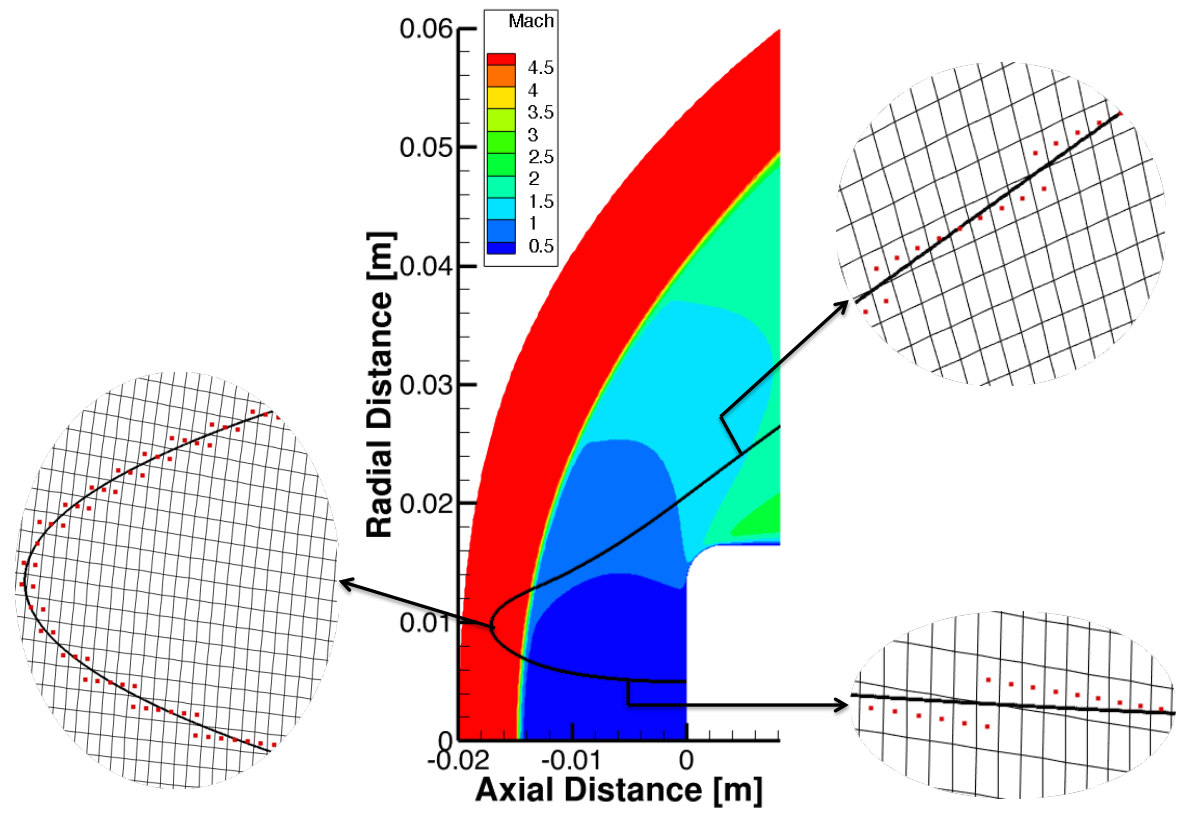

Figure 1. Computed cell-centers with regards to the trajectory of the particle

\section{II.B.3. Verification}

To verify that an accurate coupling procedure is employed, a constant spallation source term was added to a zero velocity flow field. An integration was performed over the cell volumes to evaluate the mass deposited 
by the spalled particle in the flow field. It was verified that the mass deposited in the flow field was equal to the total mass added from the source term file (constant source term $\times$ time step size $\times$ total time steps). Since the mass added by the spallation code was equivalent to the one deposited in the flow field, the applied coupling method was considered verified. Figure 2 shows a time accurate solution of zero velocity flow field when a $14 \mu \mathrm{m}$ particle is ejected with a velocity of $370 \mathrm{~m} / \mathrm{s}$ normally, $13 \mathrm{~mm}$ from the center axis. The particle deposits a source term of magnitude $10^{-18}$ throughout its travel. The particle takes 2697 iterations of time step size $10^{-7}$ to complete. The figure corresponds to solution after 600 iterations. The values of numerical mass (mass integrated over cell volumes), theoretical mass, and their relative error calculated for various iterations are given in Table 2.

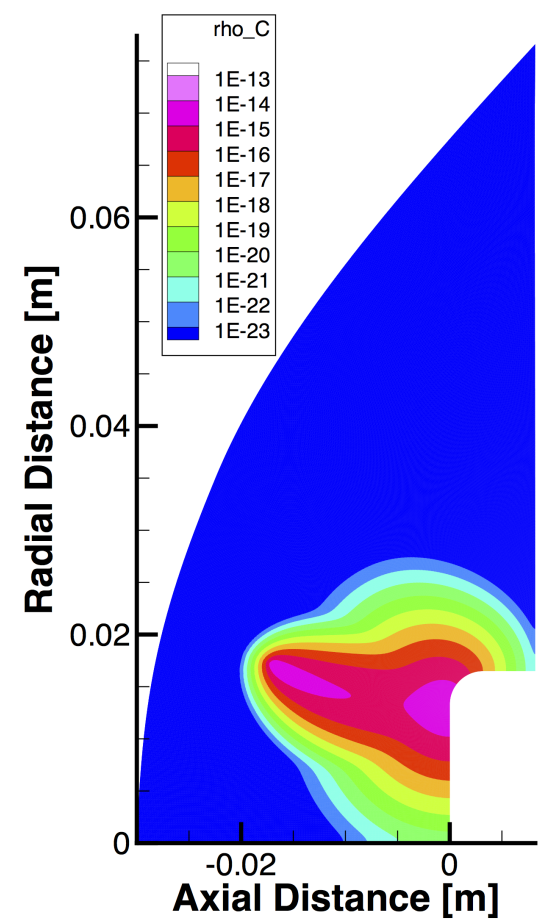

Figure 2. Carbon-vapor deposited in a zero-velocity flow field after 600 iterations

Table 2. Verification results

\begin{tabular}{cccc}
\hline \hline Iterations & Numerical Mass $(\mathrm{kg})$ & Theoretical Mass $(\mathrm{kg})$ & Relative error \\
\hline 0 & $1.83 \mathrm{E}-36$ & $0.00 \mathrm{E}+00$ & $1.83 \mathrm{E}-36$ \\
100 & $1.00 \mathrm{E}-23$ & $1.00 \mathrm{E}-23$ & $2.28 \mathrm{E}-26$ \\
200 & $2.00 \mathrm{E}-23$ & $2.00 \mathrm{E}-23$ & $8.70 \mathrm{E}-28$ \\
300 & $3.00 \mathrm{E}-23$ & $3.00 \mathrm{E}-23$ & $8.22 \mathrm{E}-27$ \\
400 & $4.00 \mathrm{E}-23$ & $4.00 \mathrm{E}-23$ & $2.14 \mathrm{E}-26$ \\
500 & $5.00 \mathrm{E}-23$ & $5.00 \mathrm{E}-23$ & $3.69 \mathrm{E}-26$ \\
600 & $6.00 \mathrm{E}-23$ & $6.00 \mathrm{E}-23$ & $3.75 \mathrm{E}-26$ \\
700 & $7.00 \mathrm{E}-23$ & $7.00 \mathrm{E}-23$ & $4.38 \mathrm{E}-26$ \\
\hline \hline
\end{tabular}

\section{Results and Discussions}

The time accurate two-way coupling solutions were computed for Mach 5 high enthalpy Argon and Air environments. Simulations for single particle as well as for multiple particles were performed. For the case 
of the single particle simulation, the coupling was performed in three stages: first, only mass coupling was included, then mass and energy coupling, and finally, complete coupling. This systematic procedure helps to track the changes in flow field properties. For the multiple particles simulation, only the complete coupling was performed.

\section{III.A. Single-particle Simulation}

\section{III.A.1. Argon flow field}

The mass removal of the spalled particle while travelling in the argon environment can only occur through sublimation. The ejection parameters and the total physical time taken by the particle to travel through the computational domain are given in Table 3.

Table 3. Ejection parameters and physical time for single particle simulation in argon environment

\begin{tabular}{ccccc}
\hline \hline Size $(\mu \mathrm{m})$ & Velocity $(\mathrm{m} / \mathrm{s})$ & Position $(\mathrm{mm})$ & Angle $\left(^{\circ}\right)$ & Physical time $(\mathrm{ms})$ \\
\hline 14 & 370 & $(0,13,0)$ & 0 & 0.2697 \\
\hline \hline
\end{tabular}

To ensure time accuracy, the solution was computed at a time step size of $4 \times 10^{-9}$, which corresponds to a maximum CFL of 0.824 . The results for mass coupling of the particle given in Table 3 are illustrated in Figs. 3, 4, 5, and 6. These figures consist of a temperature profile and density profiles of $\mathrm{C}_{1}, \mathrm{C}_{2}$, and $\mathrm{C}_{3}$ at different travel times. The temperature profile is used to indicate the position of the particle with respect to shock location, whereas the density profiles are used to determine the mass vapor deposited by the spalled particle.

Sublimation is a function of particle's temperature only. Due to the very low thermal conductivity of argon, the interaction between the particle and flow field is limited. At $70 \mu \mathrm{s}$ of the particle's travel, its temperature remains below the sublimation temperature resulting in no recession. This can be seen in Figure 3.

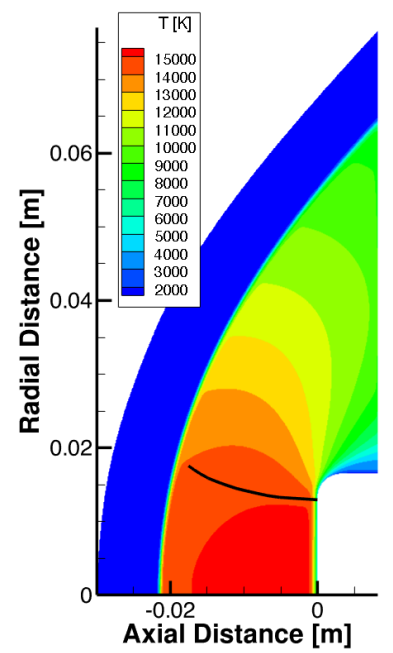

(a) Temperature

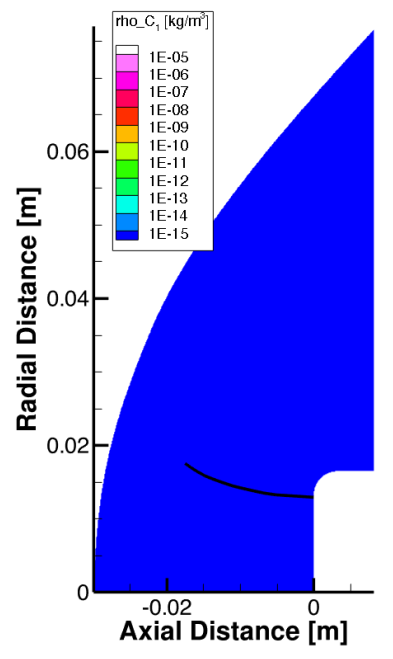

(b) $\mathrm{C}_{1}$ Density

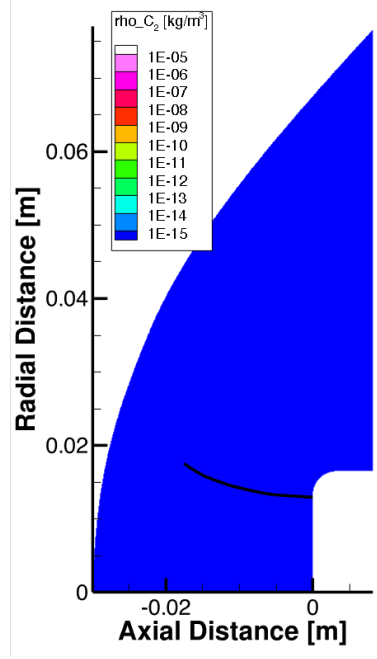

(c) $\mathrm{C}_{2}$ Density

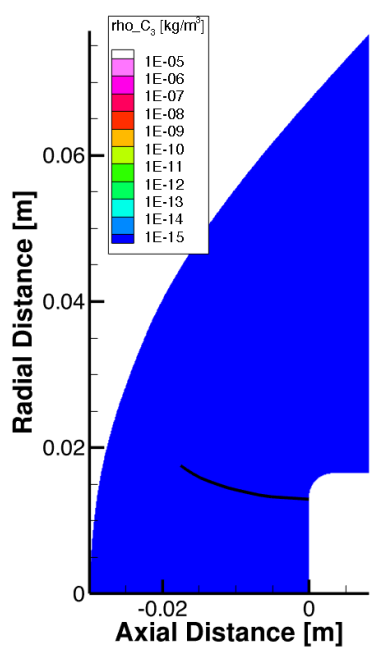

(d) $\mathrm{C}_{3}$ Density

Figure 3. Trajectory of the particle in temperature and carbon density profiles of the argon flow field at $0.07 \mathrm{milli}$ seconds

The temperature of the particle becomes greater than the sublimation temperature as it crosses the shock. At $0.15 \mathrm{~ms}$ of travel time, the particle starts sublimating as seen in Figure 4. Owing to a high temperature, the released vapor is diffused rapidly into the flow field. Additionally, the bulk velocity of the fluid directs the diffused vapor along the downstream region of the shock. 


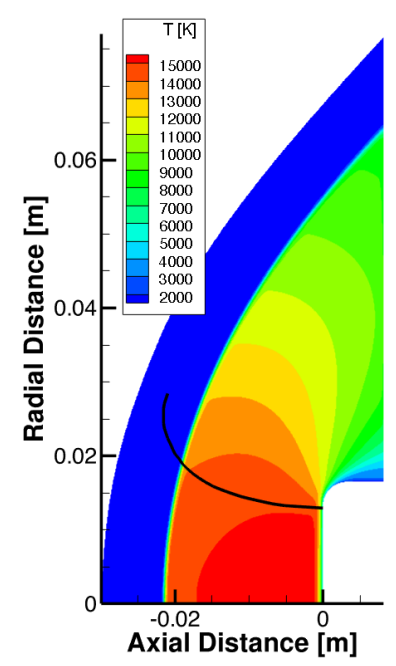

(a) Temperature

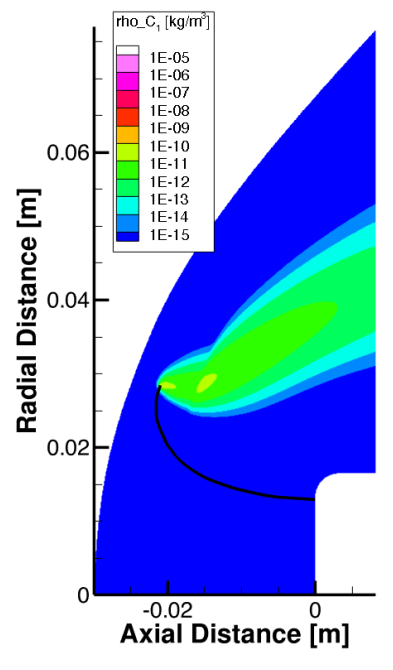

(b) $\mathrm{C}_{1}$ Density

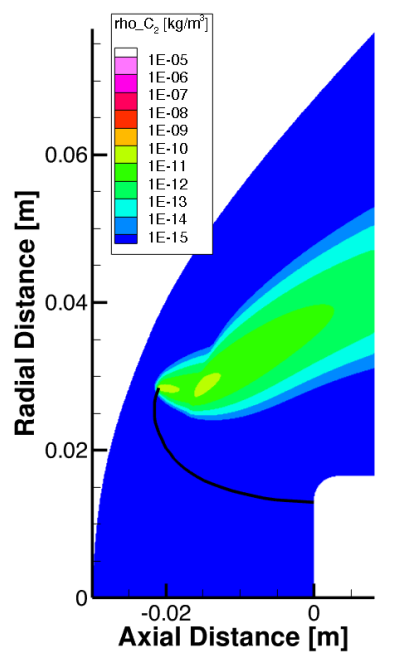

(c) $\mathrm{C}_{2}$ Density

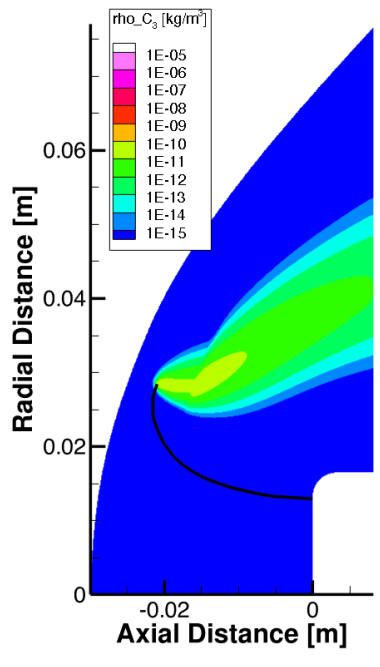

(d) $\mathrm{C}_{3}$ Density

Figure 4. Trajectory of the particle in temperature and carbon density profiles of the argon flow field at 0.15 milli seconds

At $20 \mathrm{~ms}$ of travel time, the particle is in upstream region of the shock and is about to re-enter (Figure 5). With an increase in particle's surface temperature, it sublimates more vapor and thus increasing the concentration of the diffused vapor. This diffused carbon vapor increases in magnitude when the particle is in the downstream region, immediately after reentering the post-shock region. Figure 6 shows the particle at $0.26 \mathrm{~ms}$ travel time, with additional concentration of carbon species around it.

It can be seen from the above simulation that the order of magnitude of diffused vapor decreases from $\mathrm{C}_{3}$ species to $\mathrm{C}_{1}$ species. It can be concluded that when the particle sublimates, the concentration of $\mathrm{C}_{3}$ vapor dominates other species.

The results for the mass and energy coupling, and total coupling are virtually identical as the ones obtained for mass coupling. The temperature varies by $0.01 \mathrm{~K}$ and the velocities do not change when spallation source terms are coupled. The ratio of the mass of the particle to the total mass of the flow field is very minuscule and hence, the momentum and energy source terms of spalled particle are not effective enough. However, since spallation phenomenon involves ejection of hundreds of particles, whose combined mass is comparable to the flow field mass, a noticeable change to the temperature and dynamics of the gas mixture might become apparent.

\section{III.A.2. Air flow field}

The mass removal of a spalled particle in air environment occurs by oxidation, nitridation and sublimation. The ejection parameters and physical time of the particle considered for this test-case are shown in Table 4. To achieve time accuracy, the solution was computed at a time step size of $5 \times 10^{-10}$, which corresponds to

Table 4. Ejection parameters and physical time for single particle simulation in air environment

\begin{tabular}{ccccc}
\hline \hline Size $(\mu \mathrm{m})$ & Velocity $(\mathrm{m} / \mathrm{s})$ & Position $(\mathrm{mm})$ & Angle $\left(^{\circ}\right)$ & Physical time $(\mathrm{ms})$ \\
\hline 20 & 120 & $(0,10,0)$ & 0 & 0.4580 \\
\hline \hline
\end{tabular}

a maximum CFL of 0.625. Figs. 7, 8, 9, and 10 represent the simulation results of the mass coupling for the particle given in Table 4 . The figures consists of temperature profiles and density profiles of $\mathrm{CO}, \mathrm{CN}_{1} \mathrm{C}_{1}$, $\mathrm{C}_{2}$, and $\mathrm{C}_{3}$. As opposed to the Argon flow field, which only accounted for sublimation, the air flow field also includes oxidation and nitridation that depend on the concentrations of reaction species.

Due to a high concentration of atomic oxygen and nitrogen near the surface of the material, the particle 


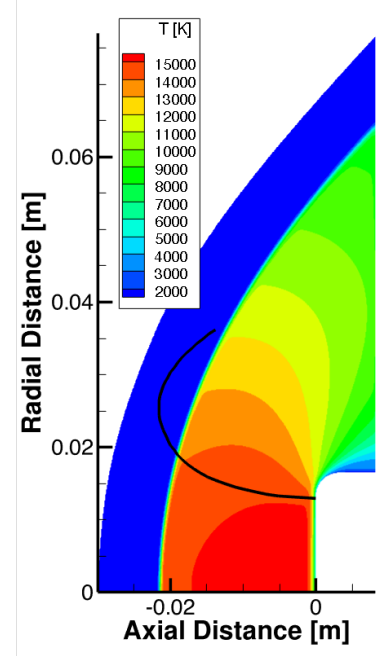

(a) Temperature

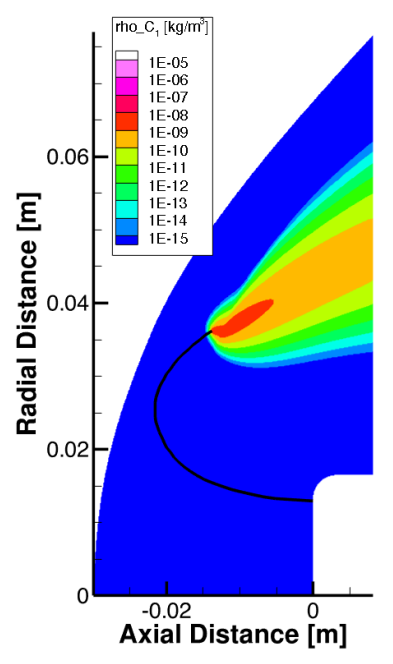

(b) $\mathrm{C}_{1}$ density

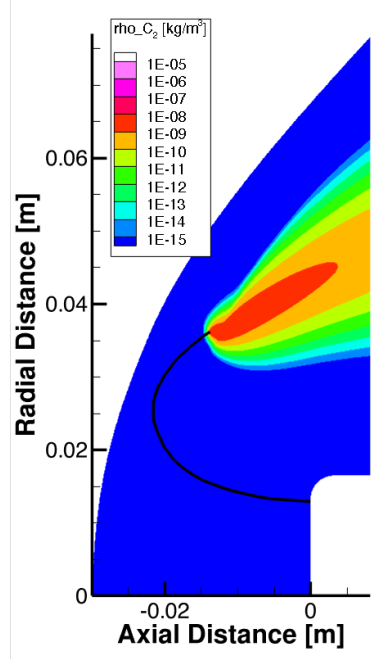

(c) $\mathrm{C}_{2}$ density

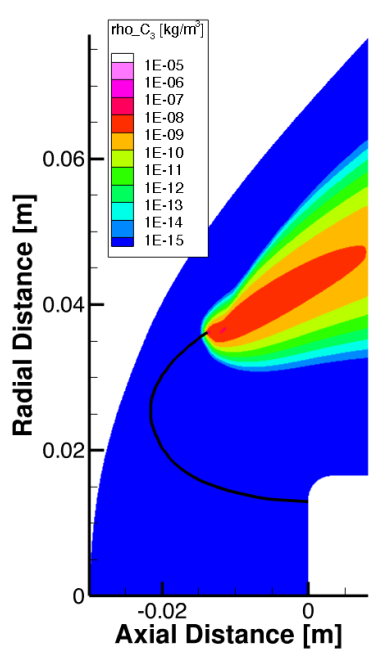

(d) $\mathrm{C}_{3}$ density

Figure 5. Trajectory of the particle in temperature and carbon density profiles of the argon flow field at 0.20 milli seconds

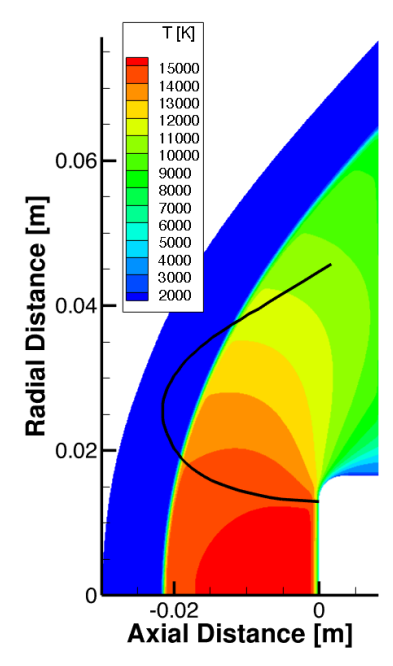

(a) Temperature

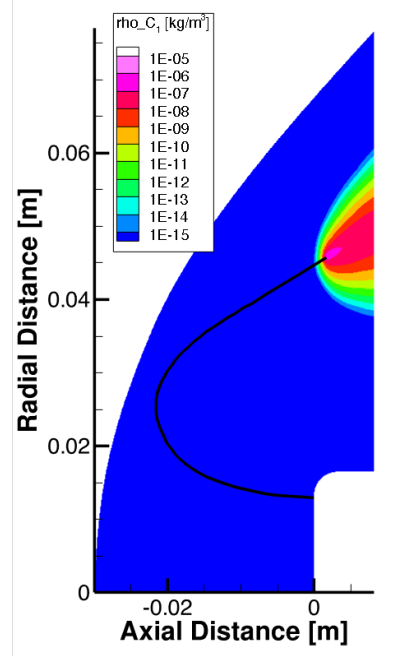

(b) $\mathrm{C}_{1}$ density

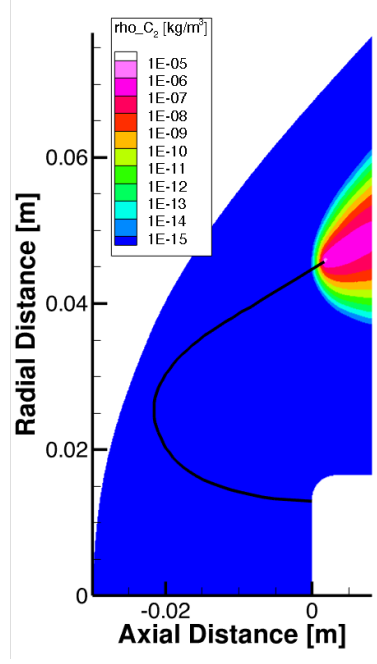

(c) $\mathrm{C}_{2}$ density

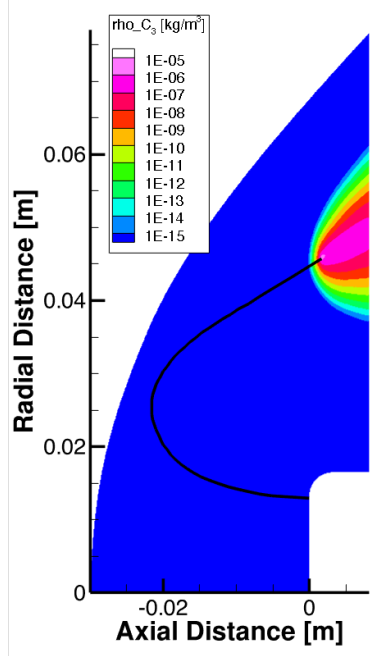

(d) $\mathrm{C}_{3}$ density

Figure 6. Trajectory of the particle in temperature and carbon density profiles of the argon flow field at 0.26 milli seconds 
reacts and releases the vapor soon after its ejection. However, the particle does not sublimate as its temperature is lower than the sublimation temperature. This behavior is shown in Figure 7 at $0.10 \mathrm{~ms}$ of its travel time.

As the particle crosses the shock, at $0.20 \mathrm{~ms}$ of its travel, it finally starts to sublimate and releases vapor of varying concentrations. The $\mathrm{CO}$ vapor's concentration decreases in the upstream region as atomic oxygen is nearly absent, and oxidation occurs only due to molecular oxygen. Also, the nitridation hardly happens in the post shock region due to nearly zero concentration of atomic nitrogen and hence, a minuscule amount of $\mathrm{CN}$ vapor is released as seen in Figure 8.

At $0.30 \mathrm{~ms}$, the particle is still in the upstream region. As its temperature increases, the concentration of sublimate vapor released increases. However, the concentration of $\mathrm{CO}$ and $\mathrm{CN}$ vapor diffused remains almost constant in this region. This behavior can be observed in Figure 9.

Figure 10 shows the particle after $0.44 \mathrm{~ms}$ of its travel. At that time, the particle is in the downstream region, and the vapor released by oxidation, nitridation, and sublimation reactions increases.

From these figures, it can be seen that the dominating species is $\mathrm{CO}$, which is released by oxidation. However, the spectroscopic experiments ${ }^{6,7}$ observed high CN spectra in the upstream region. Since nitridation cannot generate the amount of CN necessary to produce the observed quantities, other physical processes must be at play. It is hypothesized that presence of $\mathrm{CN}$ is due to the transformation of $\mathrm{CO}$ through a gas-phase exchange reaction: ${ }^{21,22}$

$$
\mathrm{CO}+\mathrm{N} \rightleftharpoons \mathrm{CN}+\mathrm{O}
$$

In order to evaluate the conversion of $\mathrm{CO}$ to $\mathrm{CN}$, this single equation is added to the flow field chemistry model of the CFD code, and the exact same simulation is performed again. Figure 11 compares the solutions of CN density profile when the exchange reaction given by Eq. 16 is considered or not. Figure $11(a)$ and $(b)$ represent the simulation of the particle at $0.20 \mathrm{~ms}$ of its travel time whereas Figure $11(c)$ and $(d)$ represent the simulation at $0.30 \mathrm{~ms}$. Fig. $11(a)$ and $(c)$ represents the $\mathrm{CN}$ density profile without adding the exchange reaction which shows that the concentration of $\mathrm{CN}$ vapor released and diffused is very small. Fig. $11(b)$ and $(d)$ illustrates the $\mathrm{CN}$ density profile when the exchange reaction is added. It is noted that there is a considerable amount of $\mathrm{CN}$ in the downstream region and very little in the upstream region. The $\mathrm{CO}$ vapor released by the particle within the shock is converted to CN. However due to a very small concentration of $\mathrm{N}$ in the post shock region, the exchange reaction is not triggered, and very low concentration of $\mathrm{CN}$ is observed. It is possible that if more reactions are considered, such as $\mathrm{CO}$ dissociation, more $\mathrm{CN}$ would be observed in the upstream region.

Similar to the results obtained in the argon environment, the mass and energy coupling, and the total coupling results are same as the mass coupling: the temperature only changes by $0.01 \mathrm{~K}$ when coupling is performed.

From these single particle simulation results, it can be seen that the particle releases vapor in both upstream region and downstream region. This reinforces the hypothesis that the presence of spalled particles ahead of the shock are the reason for the spectroscopic emissions observed in that region.

\section{III.B. Multiple Particles Simulation}

In this section, the same process described earlier is repeated, but more than one particle is ejected in the flow field, at the same time.

\section{III.B.1. Argon flow field}

The ejection parameters and physical time of the particles considered for multiple particle simulations are given in Table 5.

Figures. 12, 13, 14, and 15 illustrate the multiple particles simulation in argon flow field at different travel times. The simulation was performed at time step size of $4 \times 10^{-9}$, corresponding to a maximum CFL of 0.824, which ensure time accuracy. The behavior of the particles is similar to results observed for the single particle simulation. At $70 \mu \mathrm{s}$ from ejection, the particles approach the shock. With their temperatures less than the sublimation temperature, they show no signs of recession, as seen in Figure 12.

The particles tend to sublimate in post shock region (15 ms of travel time), releasing different vapor concentration. This vapor then convects and diffuses in a much larger region downstream, as seen in Figure 13. 


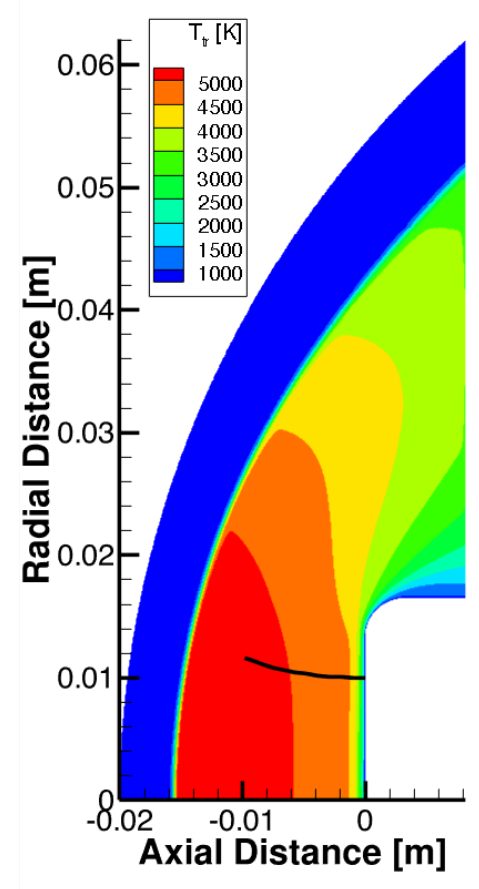

(a) Temperature

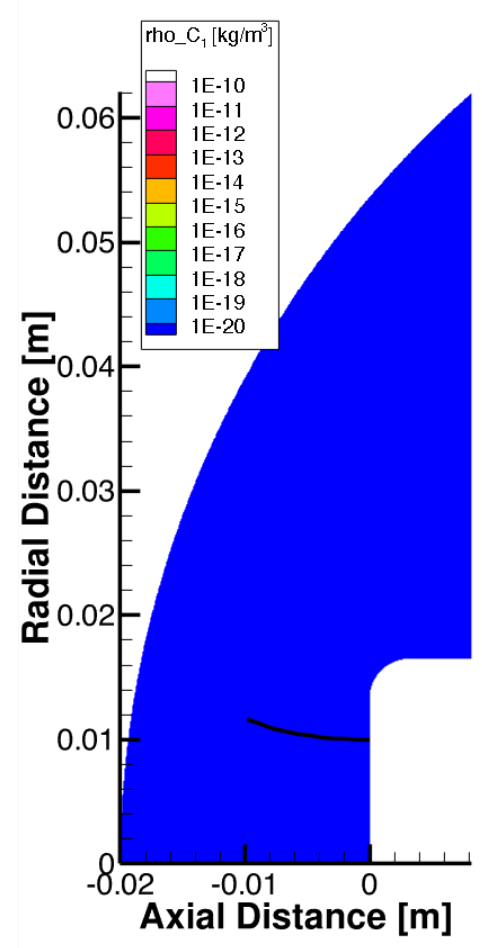

(d) $\mathrm{C}_{1}$ density

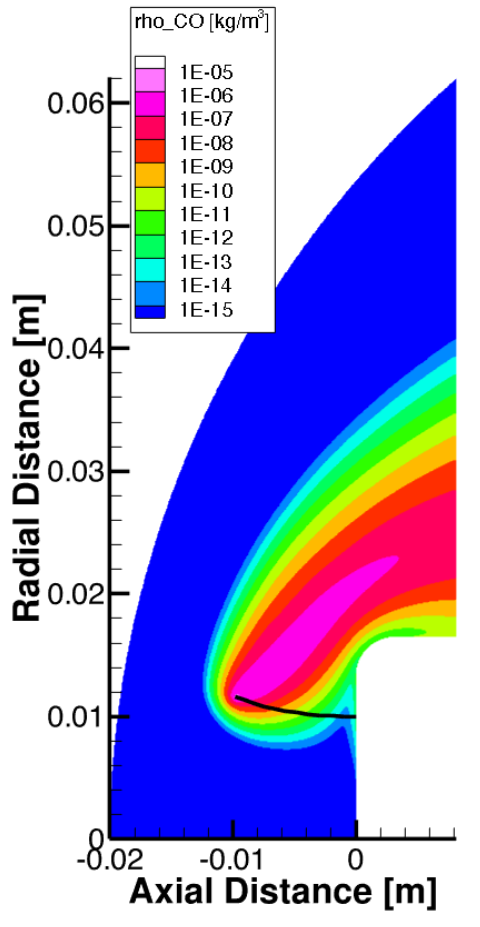

(b) CO density

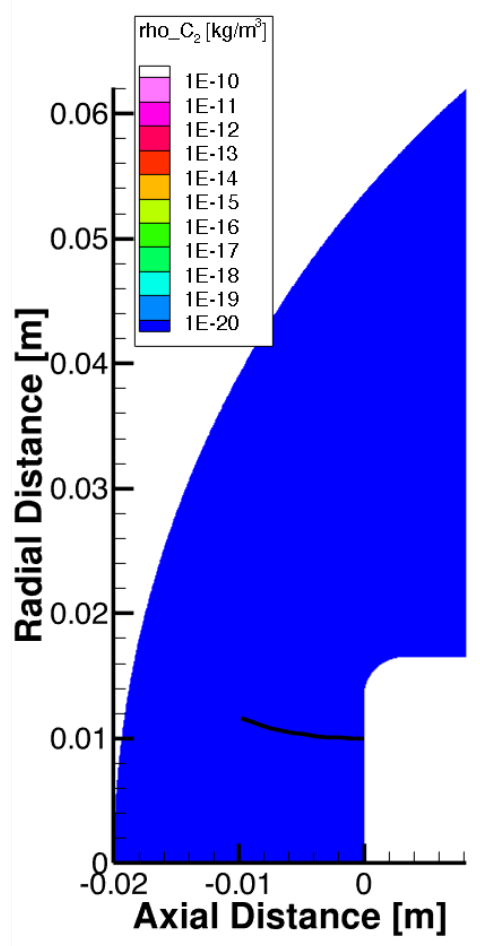

(e) $\mathrm{C}_{2}$ density

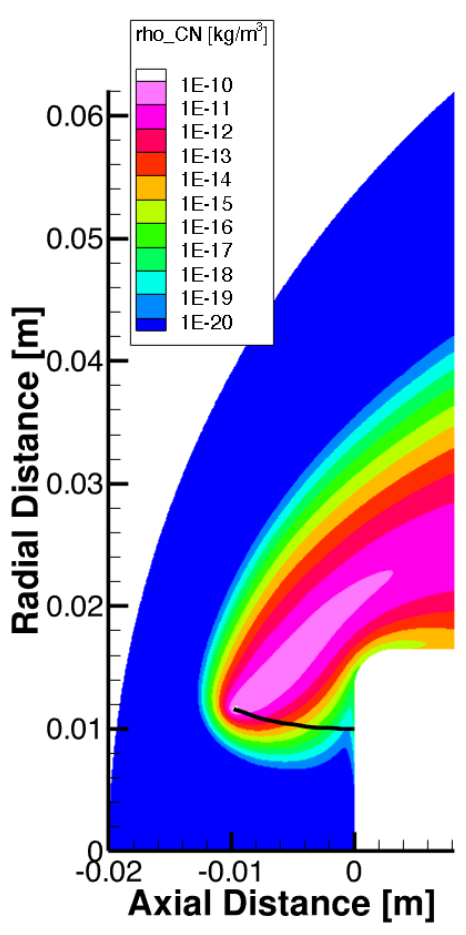

(c) CN density

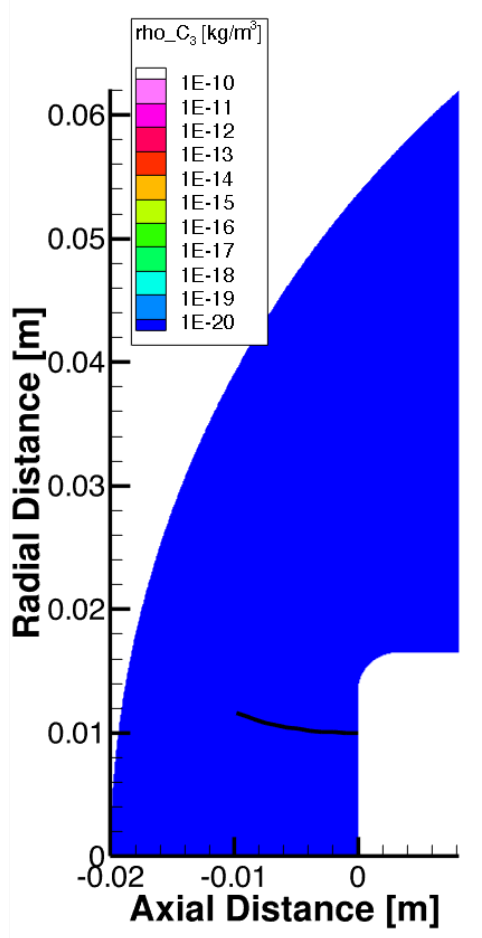

(f) $\mathrm{C}_{3}$ density

Figure 7. Trajectory of the particle in temperature and carbon (-products) density profiles of the air flow field at 0.10 milli seconds 


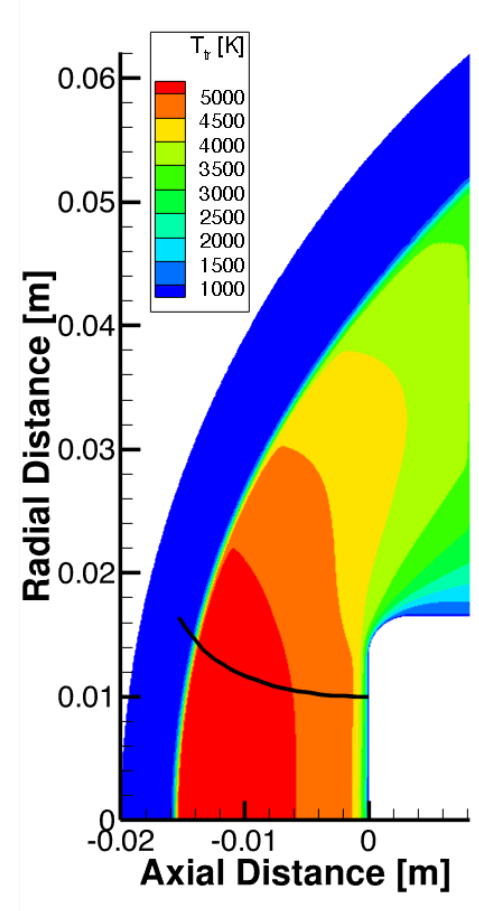

(a) Temperature

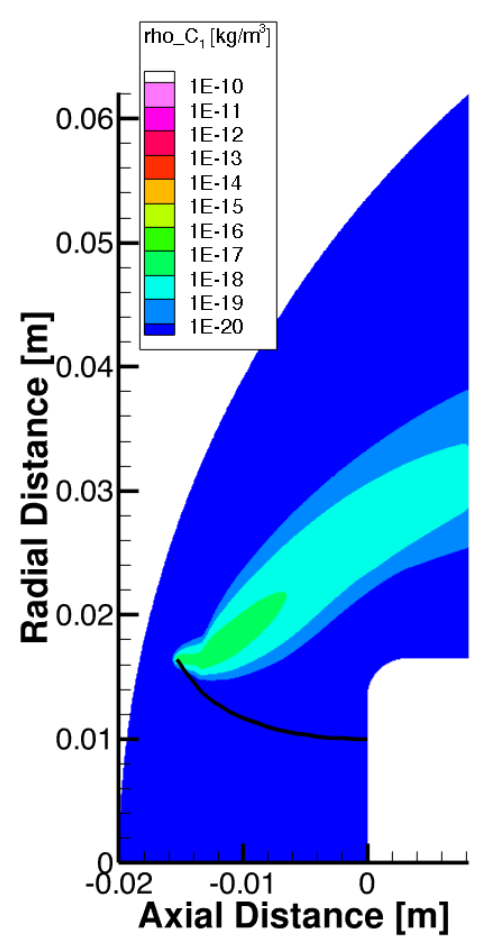

(d) $\mathrm{C}_{1}$ density

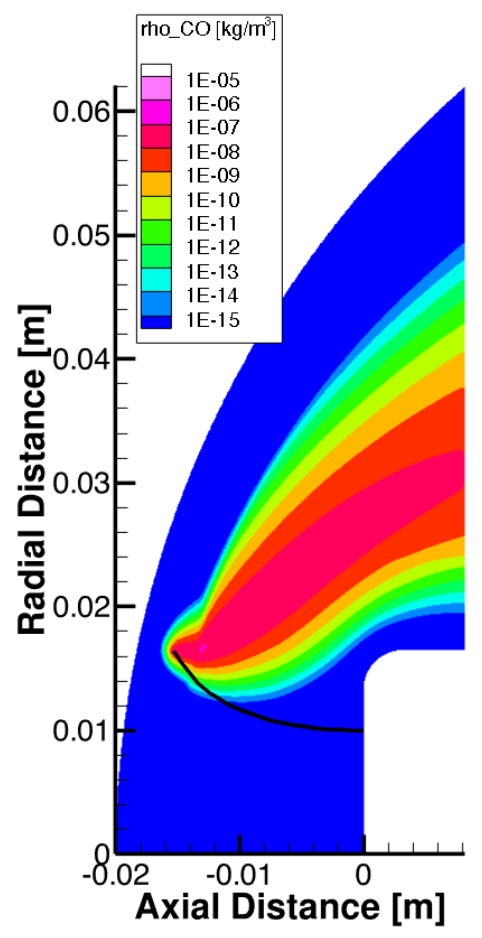

(b) CO density

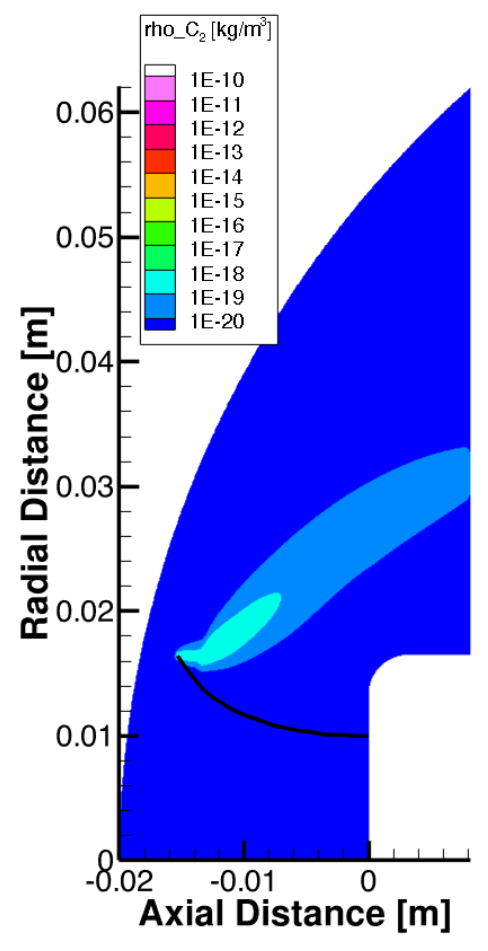

(e) $\mathrm{C}_{2}$ density

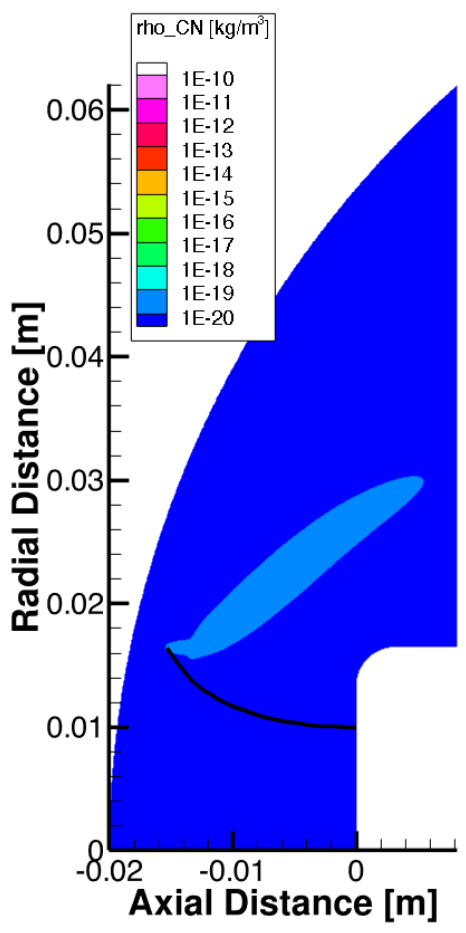

(c) CN density

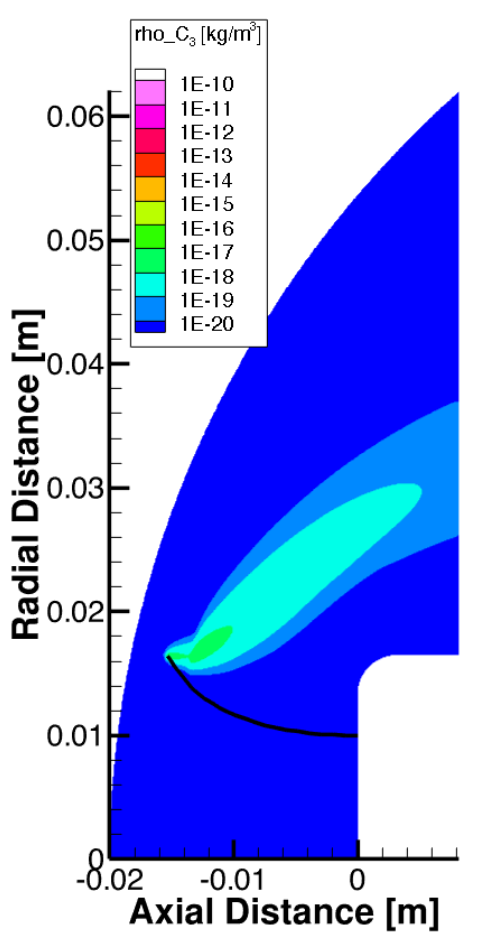

(f) $\mathrm{C}_{3}$ density

Figure 8. Trajectory of the particle in temperature and carbon (-products) density profiles of the air flow field at 0.20 milli seconds 


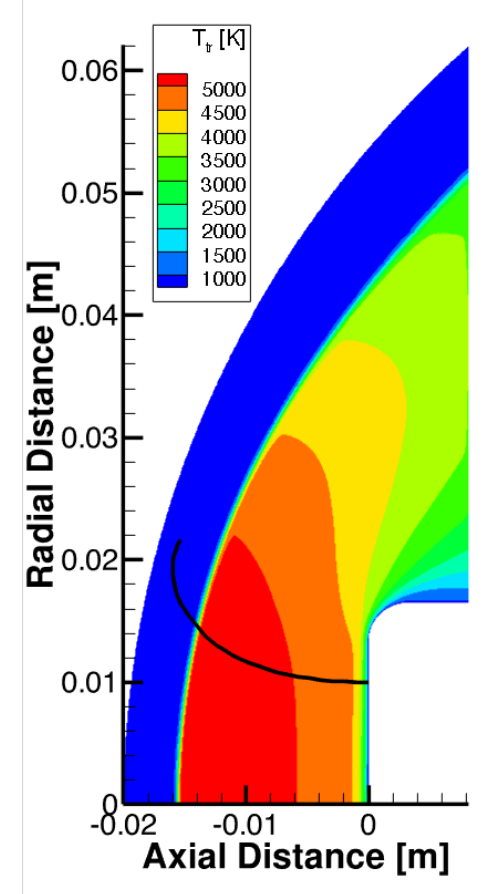

(a) Temperature

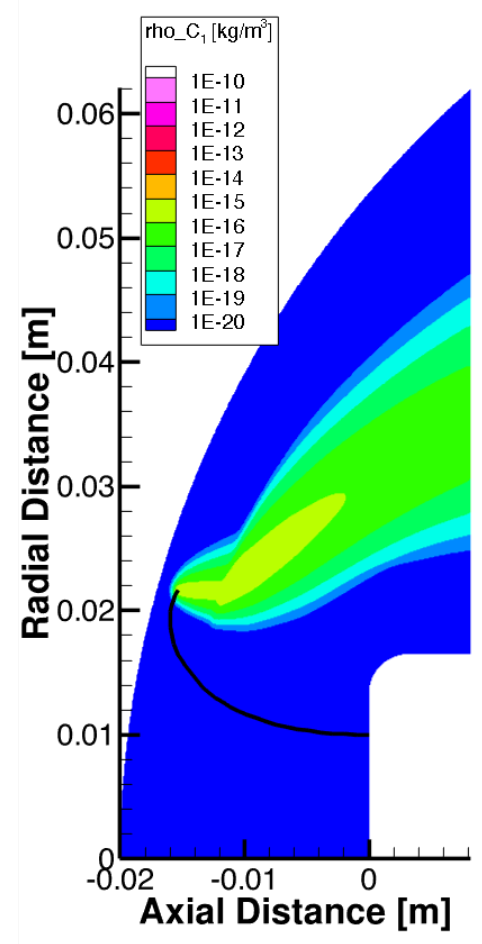

(d) $\mathrm{C}_{1}$ density

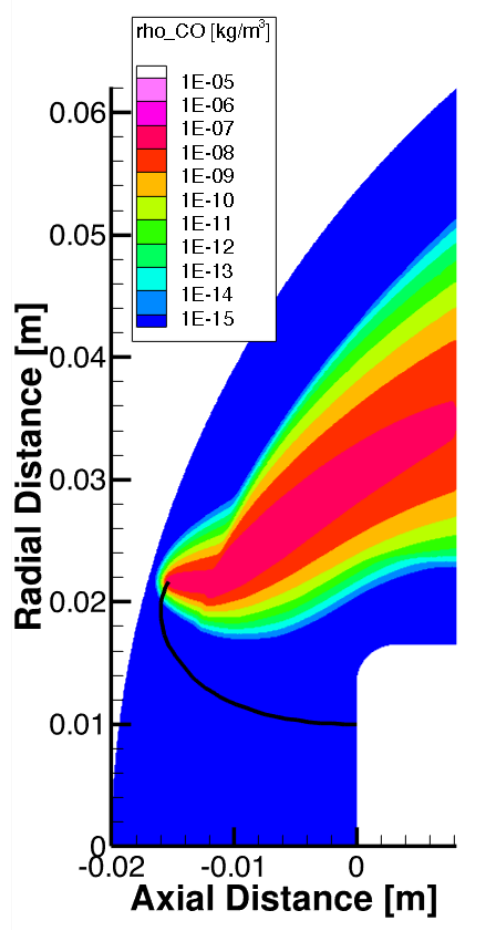

(b) CO density

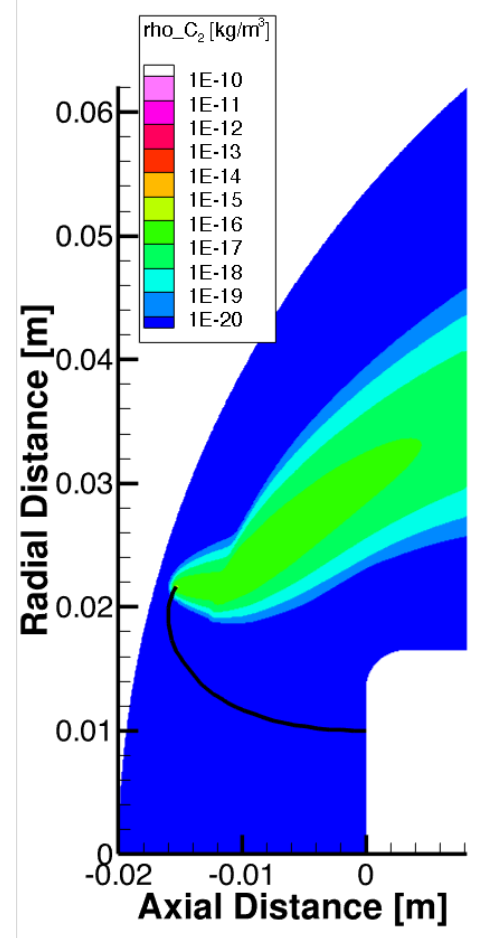

(e) $\mathrm{C}_{2}$ density

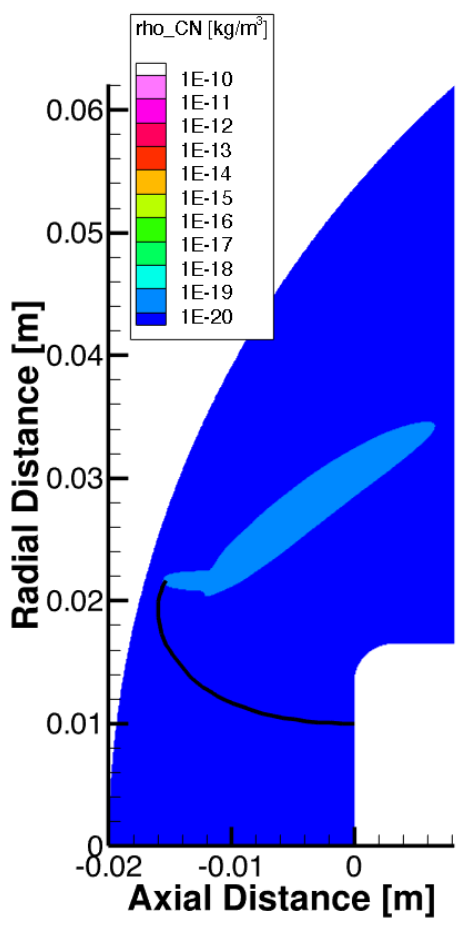

(c) CN density

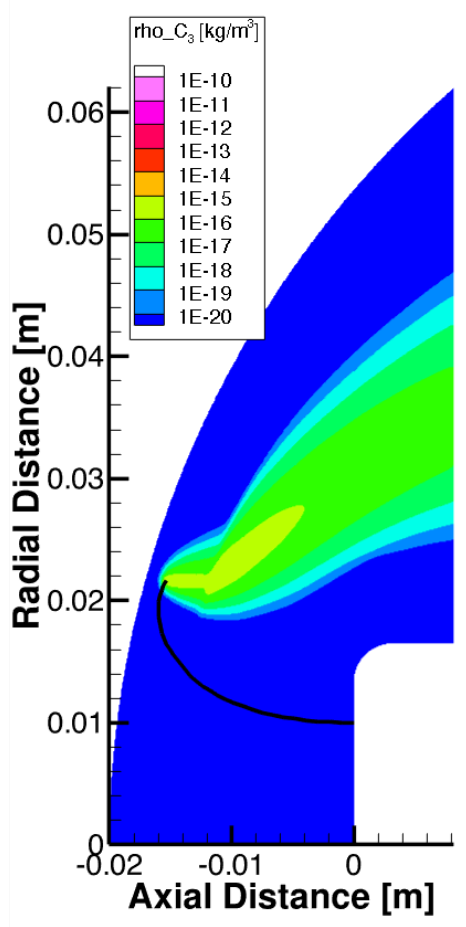

(f) $\mathrm{C}_{3}$ density

Figure 9. Trajectory of the particle in temperature and carbon (-products) density profiles of the air flow field at 0.30 milli seconds 


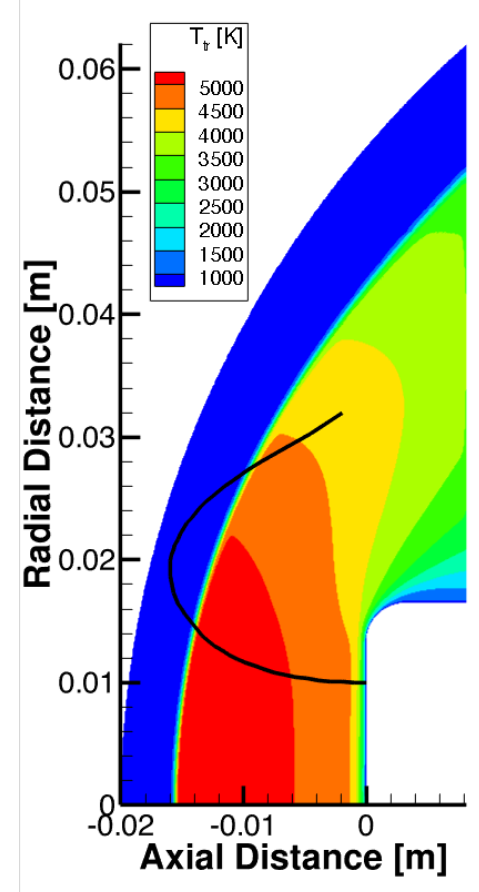

(a) Temperature

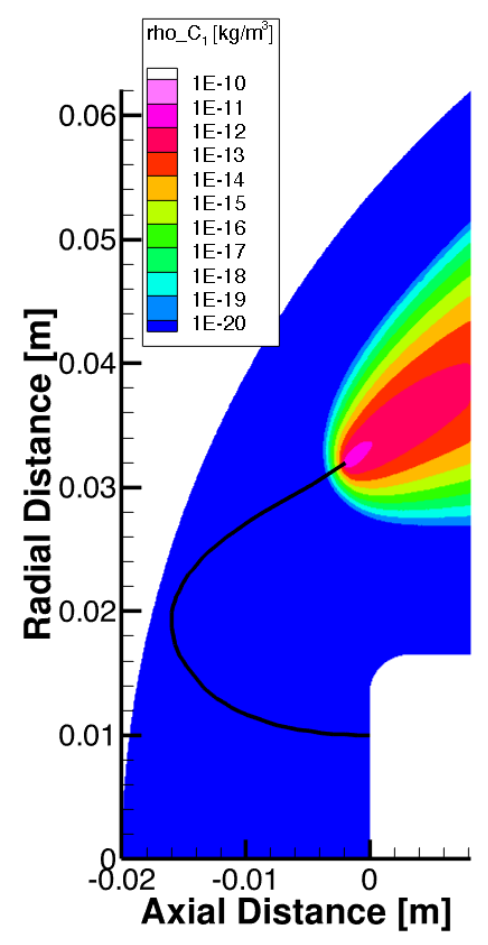

(d) $\mathrm{C}_{1}$ density

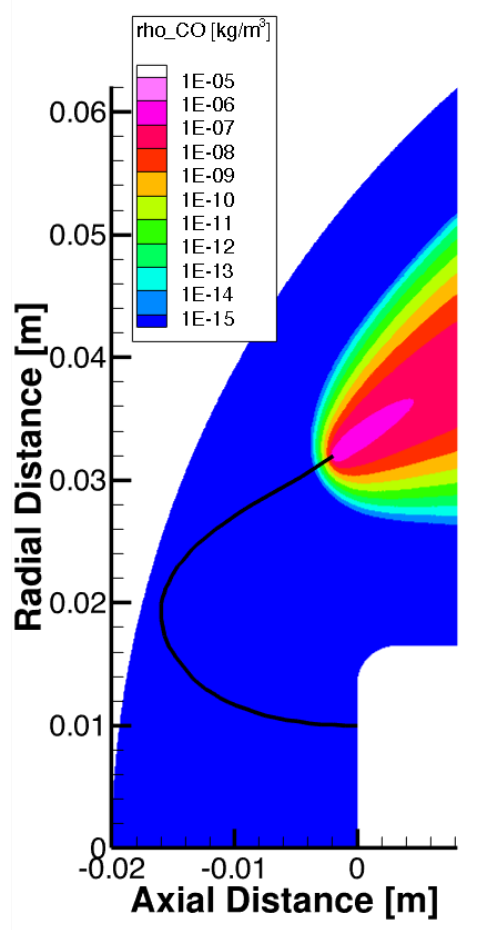

(b) CO density

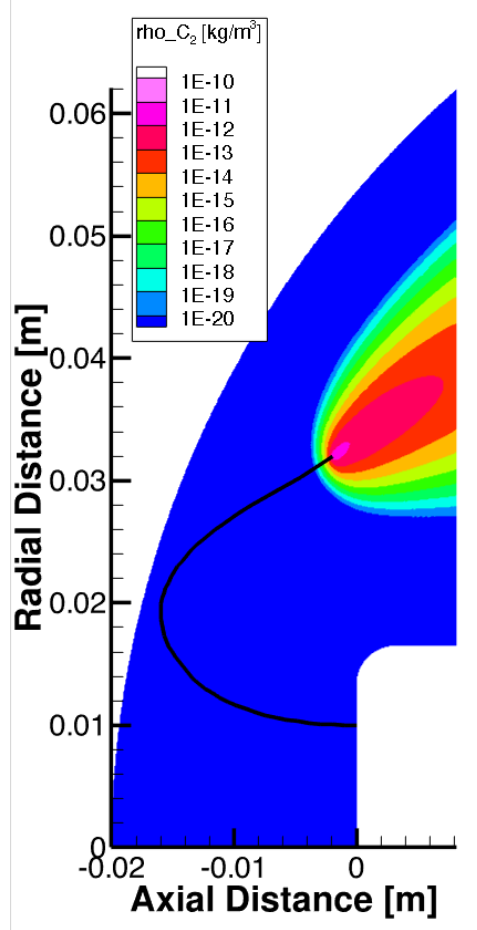

(e) $\mathrm{C}_{2}$ density

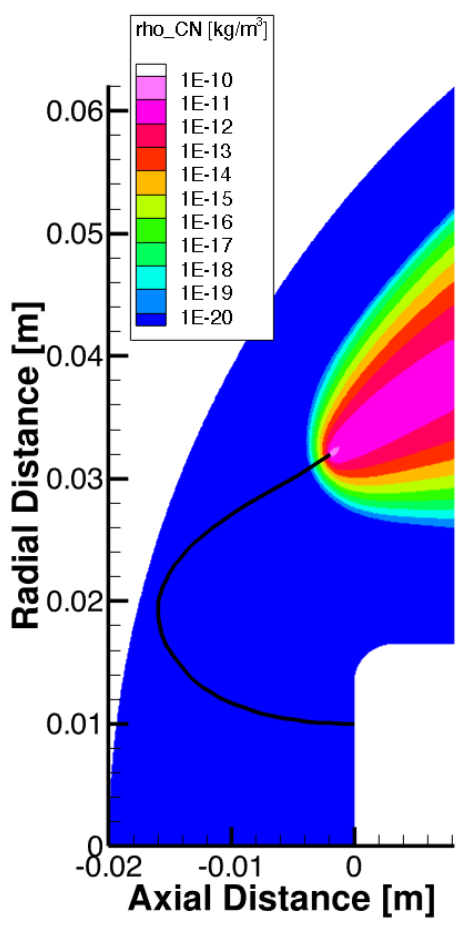

(c) CN density

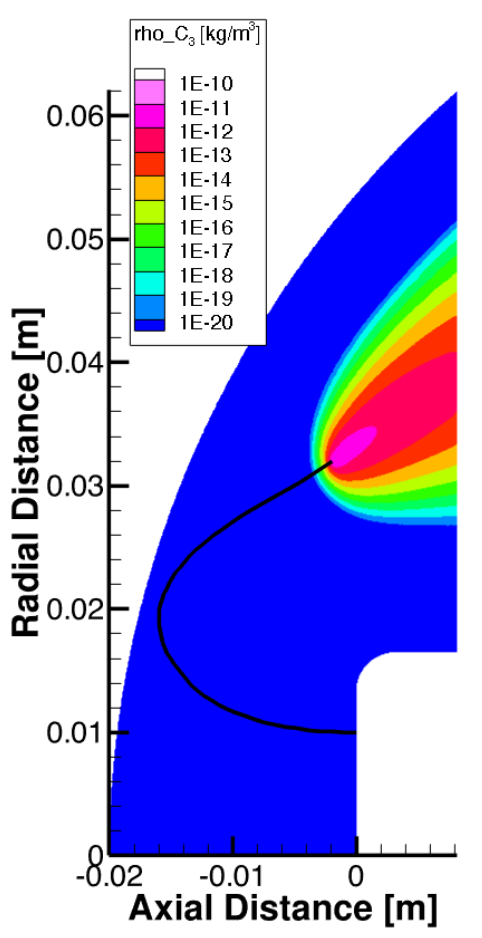

(f) $\mathrm{C}_{3}$ density

Figure 10. Trajectory of the particle in temperature and carbon (-products) density profiles of the air flow field at 0.44 ms 


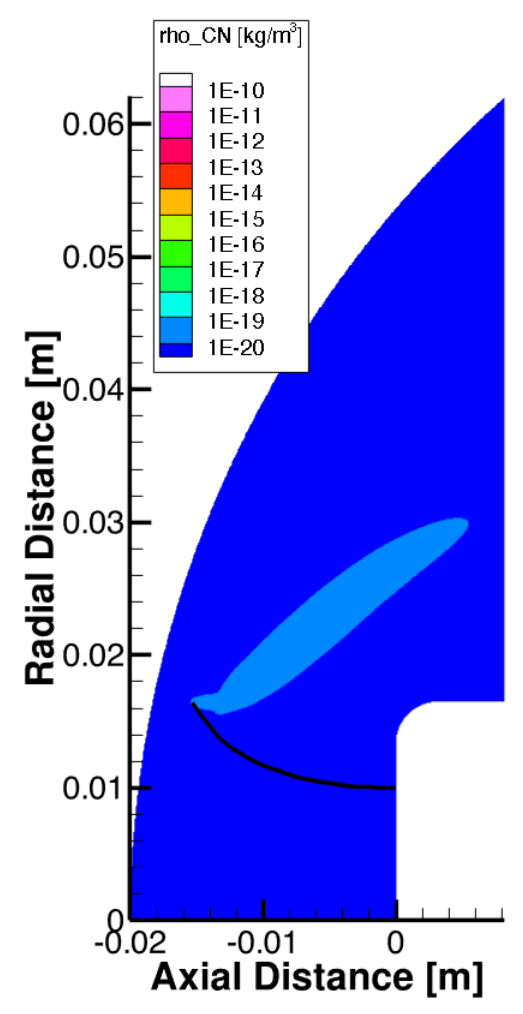

(a) CN density at 0.20 milli seconds (without exchange reaction)

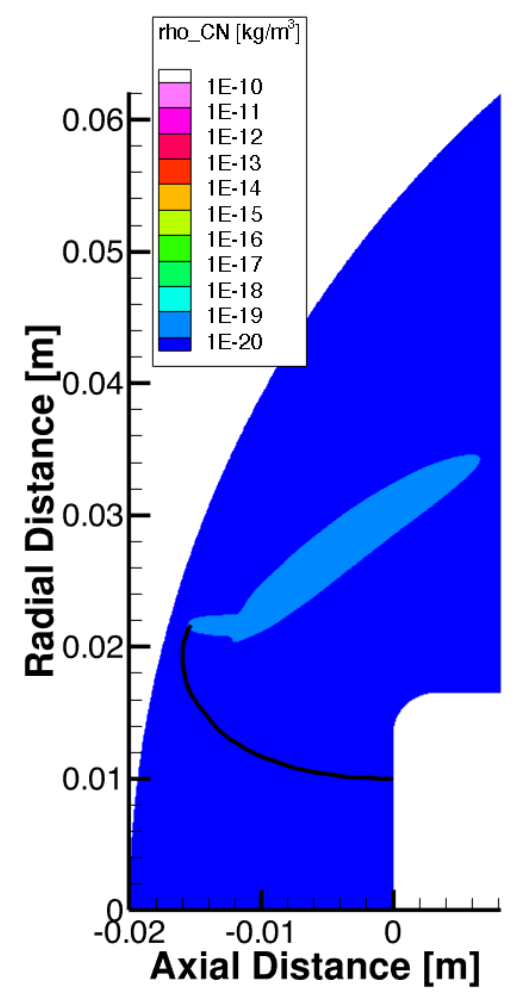

(c) $\mathrm{CN}$ density at 0.30 milli seconds (without exchange reaction)

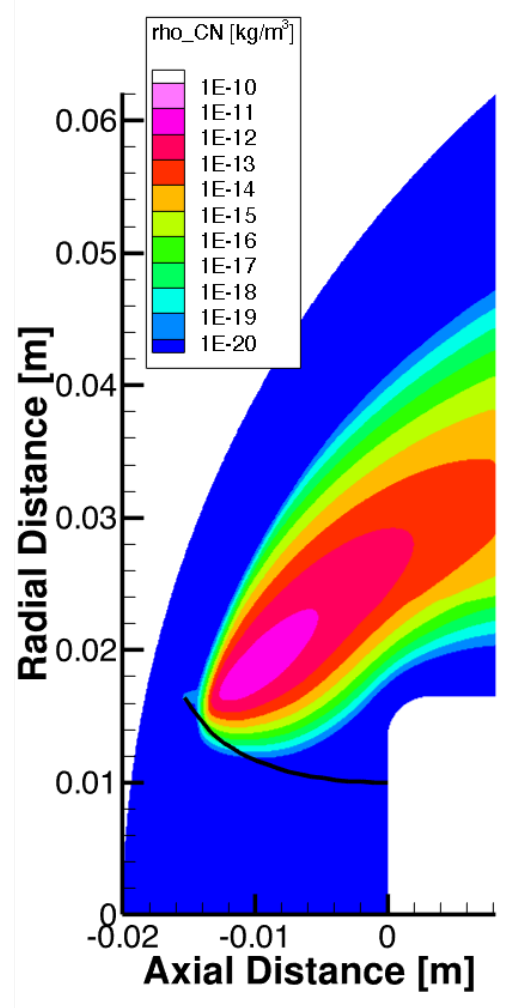

(b) CN density at 0.20 milli seconds (with exchange reaction)

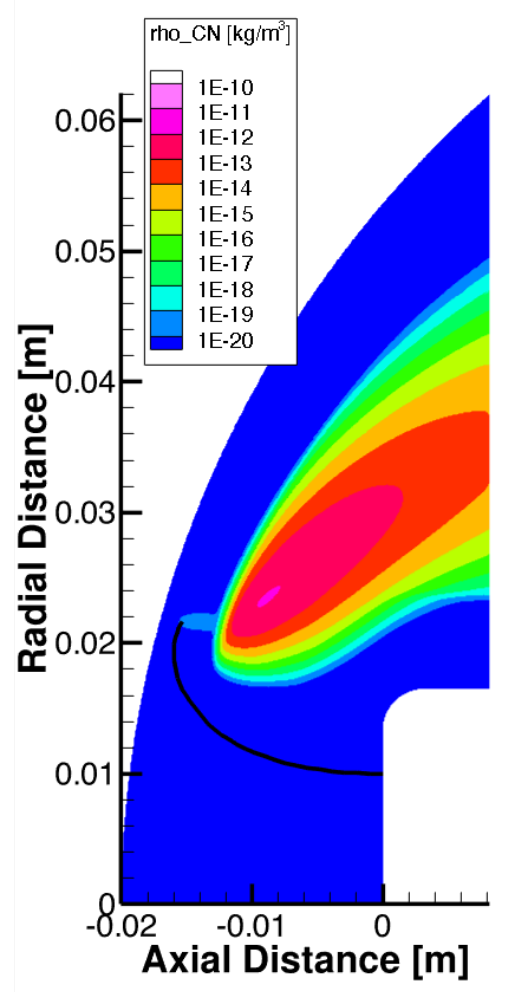

(d) CN density at 0.30 milli seconds (with exchange reaction)

Figure 11. CN density profiles without and with the exchange reaction at 0.20 and 0.30 milli seconds 
Table 5. Ejection parameters and physical time for multiple particles simulation in argon environment

\begin{tabular}{ccccc}
\hline \hline Size $(\mu \mathrm{m})$ & Velocity $(\mathrm{m} / \mathrm{s})$ & Position $(\mathrm{mm})$ & Angle $\left(^{\circ}\right)$ & Physical time $(\mathrm{ms})$ \\
\hline 12 & 380 & $(0,10,0)$ & 0 & 0.2370 \\
14 & 370 & $(0,13,0)$ & 0 & 0.2697 \\
16 & 360 & $(0,07,0)$ & 0 & 0.3323 \\
\hline \hline
\end{tabular}

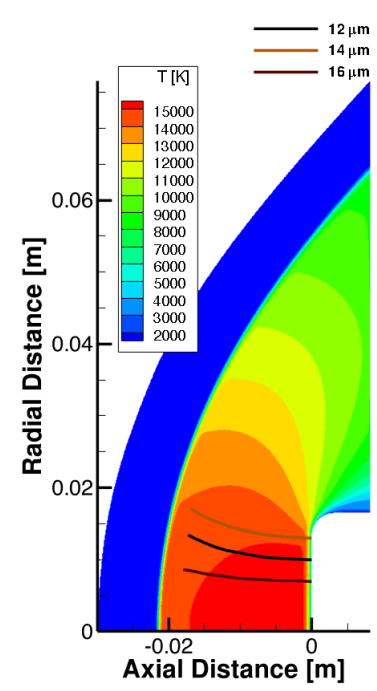

(a) Temperature

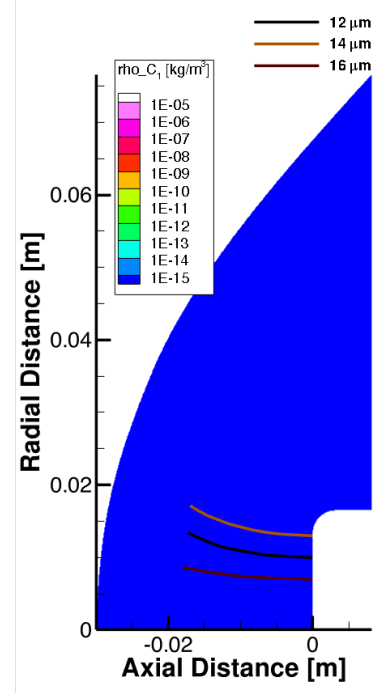

(b) $\mathrm{C}_{1}$ Density

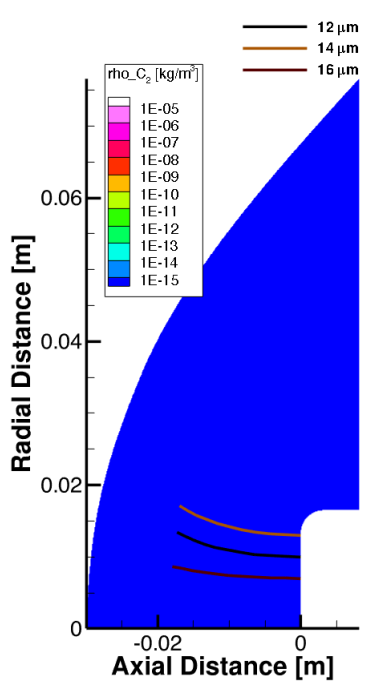

(c) $\mathrm{C}_{2}$ Density

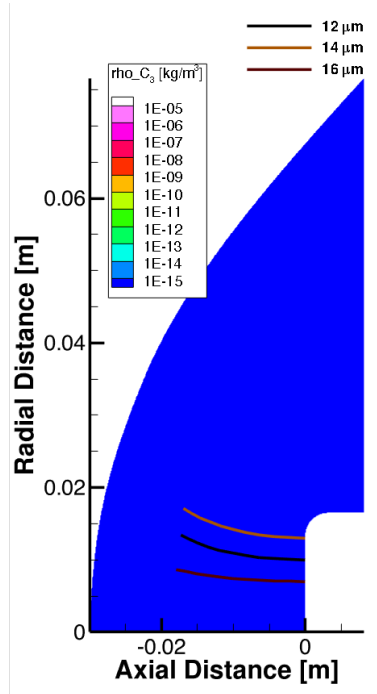

(d) $\mathrm{C}_{3}$ Density

Figure 12. Trajectories of the particles in temperature and carbon density profiles of the argon flow field at 0.07 ms

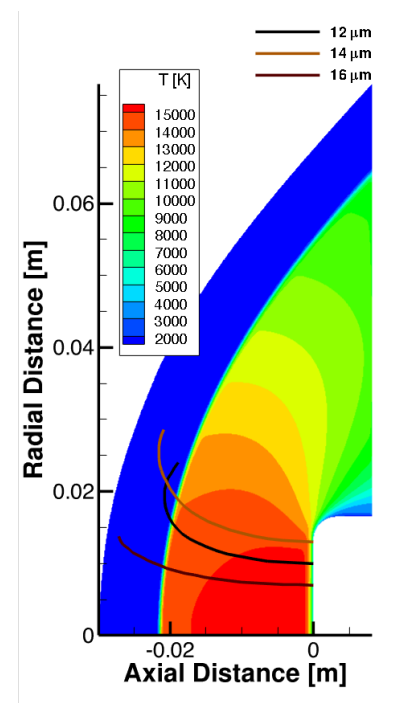

(a) Temperature

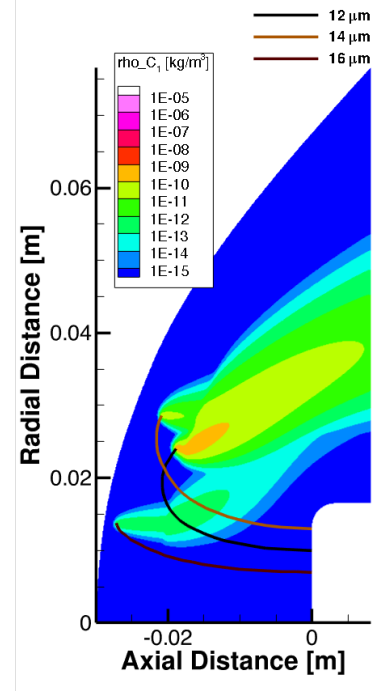

(b) $\mathrm{C}_{1}$ Density

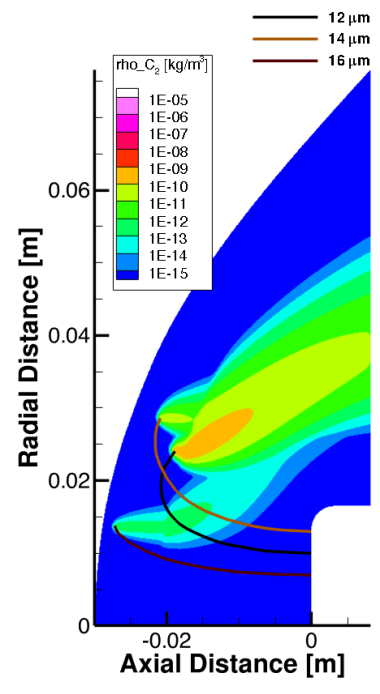

(c) $\mathrm{C}_{2}$ Density

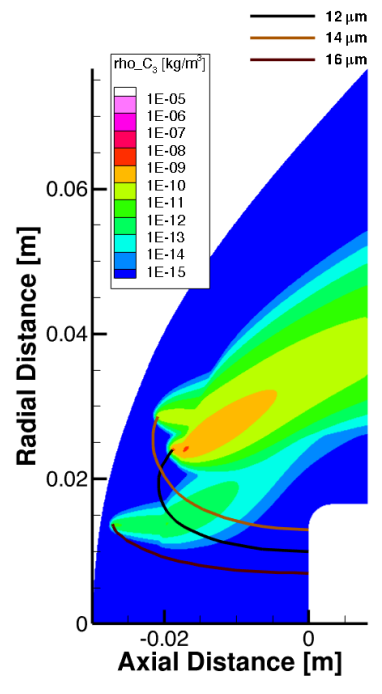

(d) $\mathrm{C}_{3}$ Density

Figure 13. Trajectories of the particles in temperature and carbon density profiles of the argon flow field at 0.15 milli seconds 
At travel time of $0.23 \mathrm{~ms}$, two of the particles re-renter the shock region as shown in Figure 14. The concentrations of the carbon vapor released increases significantly and propagates to a much larger area. As soon as these two particles complete their travel in the computational domain, the diffused vapor area

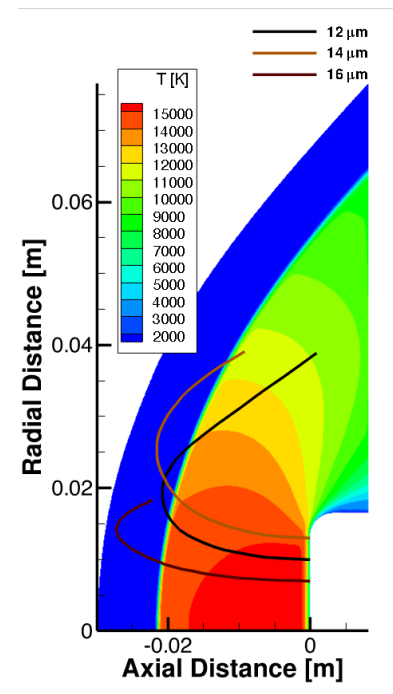

(a) Temperature

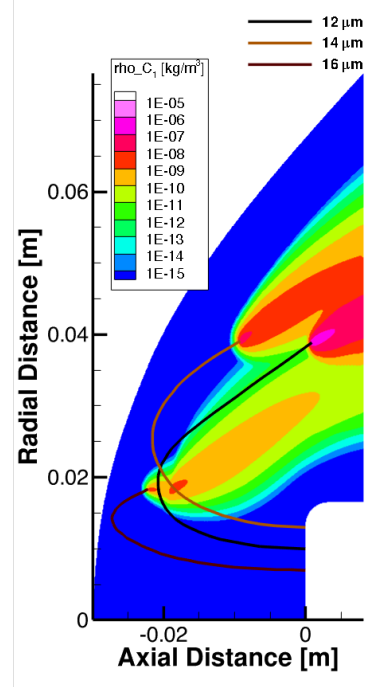

(b) $\mathrm{C}_{1}$ Density

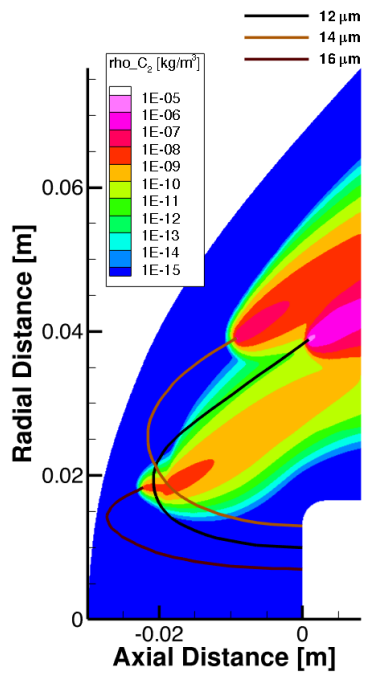

(c) $\mathrm{C}_{2}$ Density

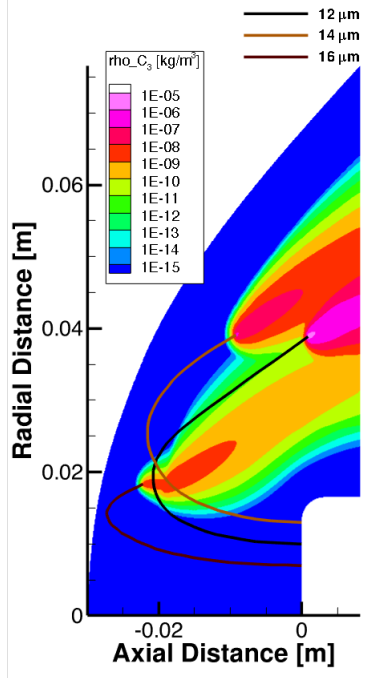

(d) $\mathrm{C}_{3}$ Density

Figure 14. Trajectories of the particles in temperature and carbon density profiles of the argon flow field at 0.23 milli seconds

decreases and the contribution only comes from the third particle, as shown in Figure 15. It is noticed that even with multiple spalled particles in the flow field, the temperature only changes by a maximum of $0.1 \mathrm{~K}$. The other parameters remain same throughout the simulation.

\section{III.B.2. Air flow field}

The ejection parameter for the particles simulated in this section are given in Table 6. The solution is computed at a time step size of $8 \times 10^{-10}$, which corresponds to a maximum CFL of 1.000 , to maintain time accuracy.

Table 6. Ejection parameters and physical time for multiple particles simulation in air environment

\begin{tabular}{ccccc}
\hline \hline Size $(\mu \mathrm{m})$ & Velocity $(\mathrm{m} / \mathrm{s})$ & Position $(\mathrm{mm})$ & Angle $\left(^{\circ}\right)$ & Physical time $(\mathrm{ms})$ \\
\hline 15 & 70 & $(0,05,0)$ & 0 & 0.1866 \\
20 & 120 & $(0,10,0)$ & 0 & 0.4580 \\
25 & 100 & $(0,13,0)$ & 0 & 0.5590 \\
30 & 85 & $(0,08,0)$ & 0 & 0.5744 \\
\hline \hline
\end{tabular}

The particles of size $20 \mu \mathrm{m}, 25 \mu \mathrm{m}$, and $30 \mu \mathrm{m}$ penetrate through the shock, whereas the $15 \mu \mathrm{m}$ does not. The behavior of these particles are shown in Figs. 16, 17, 18, and 19 at the respective times.

At $0.09 \mathrm{~ms}$, the particles start diffusing large concentrations of $\mathrm{CO}$ and $\mathrm{CN}$ vapors. However, the particles hardly sublimate as their temperature is below sublimation temperature. The simulation at this time is illustrated in Fig. 16. The released vapor is seen to diffuse over a larger area, and also observed to diffuse towards the center-line direction.

Figure 17 shows the simulation at $0.19 \mathrm{~ms}$. At this time, the $20 \mu \mathrm{m}$ particle passes through the shock, the $25 \mu \mathrm{m}$ particle almost enters the shock, while the $30 \mu \mathrm{m}$ particle still travels towards the shock. The $15 \mu \mathrm{m}$ particle, however, has already changed direction while in the high temperature region, and will never reach the shock. The contribution to $\mathrm{CO}$ vapor density decreases from particles that cross the shock and remains almost the same from the particles that are in the downstream region. Similarly, the particles that 


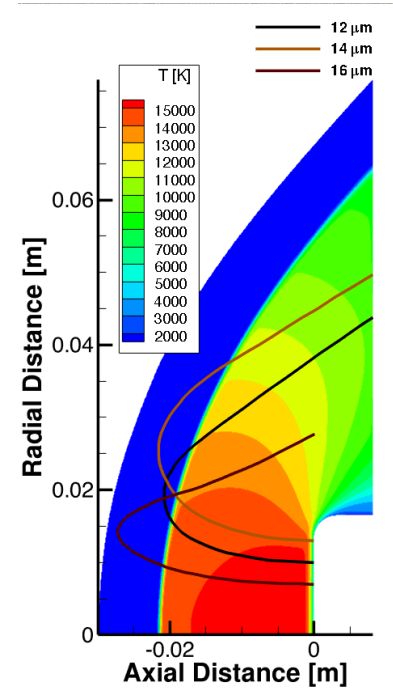

(a) Temperature

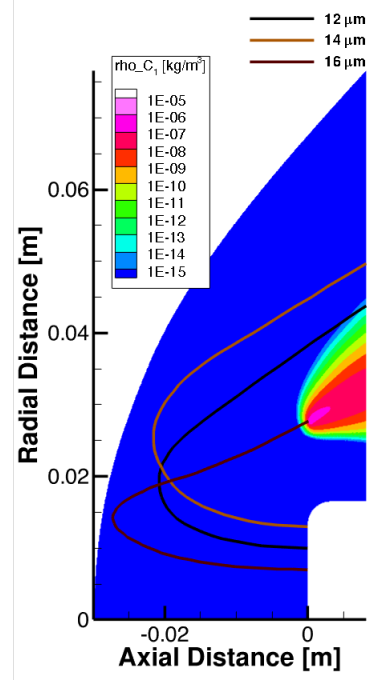

(b) $\mathrm{C}_{1}$ Density

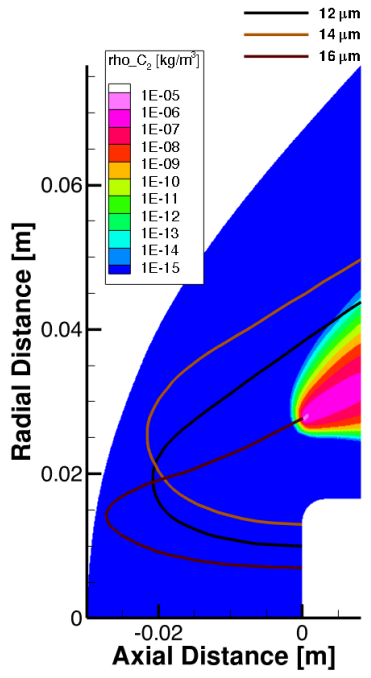

(c) $\mathrm{C}_{2}$ Density

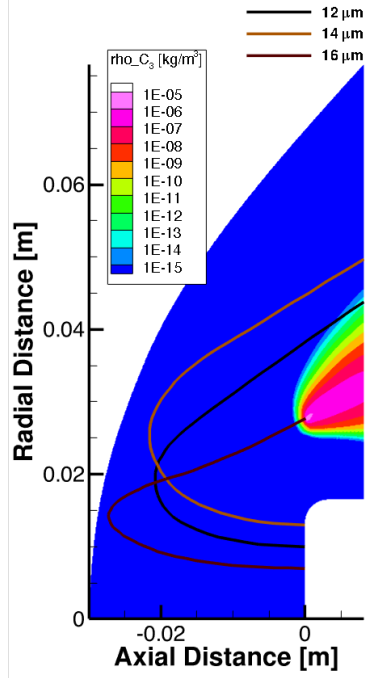

(d) $\mathrm{C}_{3}$ Density

Figure 15. Trajectories of the particles in temperature and carbon density profiles of the argon flow field at 0.33 milli seconds

cross the shock contribute to a very small $\mathrm{CN}$ vapor and the other particles contribute to the moderate concentration. The $15 \mu \mathrm{m}$ particle starts sublimating and being in a low velocity zone, the diffused vapor tend to move towards the center-line. The $20 \mu \mathrm{m}$ and $25 \mu \mathrm{m}$ particles also sublimate, contributing a very small amount of $\mathrm{C}_{1}, \mathrm{C}_{2}$, and $\mathrm{C}_{3}$ vapors.

At $0.35 \mathrm{~ms}, 20 \mu \mathrm{m}, 25 \mu \mathrm{m}$, and $30 \mu \mathrm{m}$ particles are in the post-shock region, whereas $15 \mu \mathrm{m}$ particle completes its travel, moving out of the computational domain. The $\mathrm{CO}$ vapor concentration decreases, and CN vapor becomes negligible. This behavior is seen in Figure 18. It is also observed that a small amount of $\mathrm{CO}$ and $\mathrm{CN}$ concentrations remains close the surface of the ablator.

At $0.55 \mathrm{~ms}$ of time, $20 \mu \mathrm{m}$ particle exits the domain, and the other two particles $(25 \mu \mathrm{m}, 30 \mu \mathrm{m})$ enter the downstream region. The $\mathrm{CO}, \mathrm{CN}, \mathrm{C}_{1}, \mathrm{C}_{2}$, and $\mathrm{C}_{3}$ concentrations seem to increase in magnitude, as illustrated in Figure 19. However, a small amount of concentration of $\mathrm{CO}$ and $\mathrm{CN}$ remains close to the ablator.

Apart from the effect on the composition of the flow field, the multiple particles simulation has a very small effect on the temperature and velocity field. It is observed that the translational temperature changes by $0.3 \mathrm{~K}$ and vibrational temperature changes by $0.05 \mathrm{~K}$. Also, the velocity field in $y$-direction shows regions of change in velocity in the post-shock region. Figure 20 illustrates these changes in the upstream region at $0.35 \mathrm{~ms}$. The position of particles is shown in Fig.18 (a). It is noticed that there is a change of $0.03 \mathrm{~m} / \mathrm{s}$ of velocity in y-direction.

The results from the multiple particles simulations illustrate that the products released from the particle convect and diffuse over a larger area. The presence of released vapor might be effective in altering the aerodynamic heat rates at the surface of the sample. It also provides an explanation on why the heat rates have been under-predicted in downstream region in the past studies.

\section{Conclusion}

A two-way loose coupling was achieved using spallation code and a CFD code. The results obtained through this coupling allowed to assess the spalled particle effect on the flow field.

Initially, the coupling is performed for a single particle spalled in a Mach 5 argon and air environments. The results in the argon flow showed that the particle starts releasing the sublimate vapor once it crosses the shock, and its concentration keeps increasing as it moves through the computational domain. It is also observed that the magnitude of concentration of sublimate vapor increases from $\mathrm{C}_{1}$ species to $\mathrm{C}_{3}$ species at any point of the particle's travel. In air environment, the particle reacts and releases the vapor soon after 


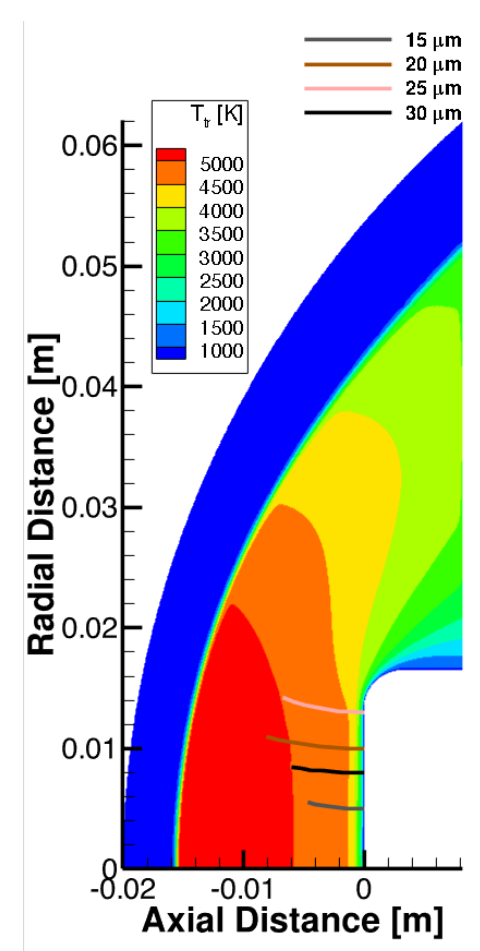

(a) Temperature

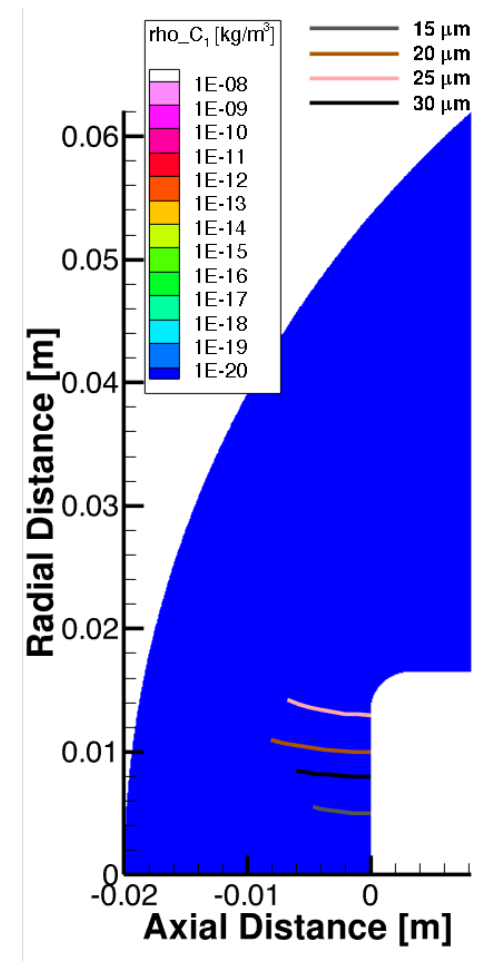

(d) $\mathrm{C}_{1}$ Density

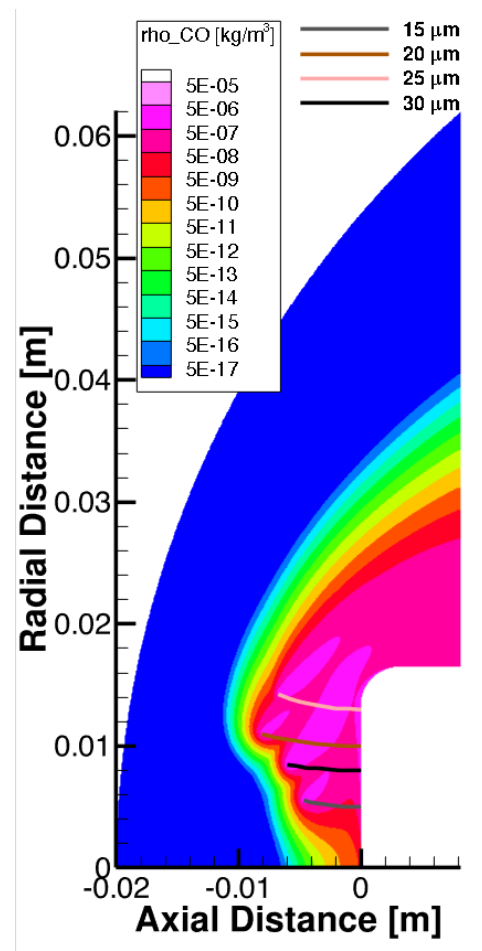

(b) CO Density

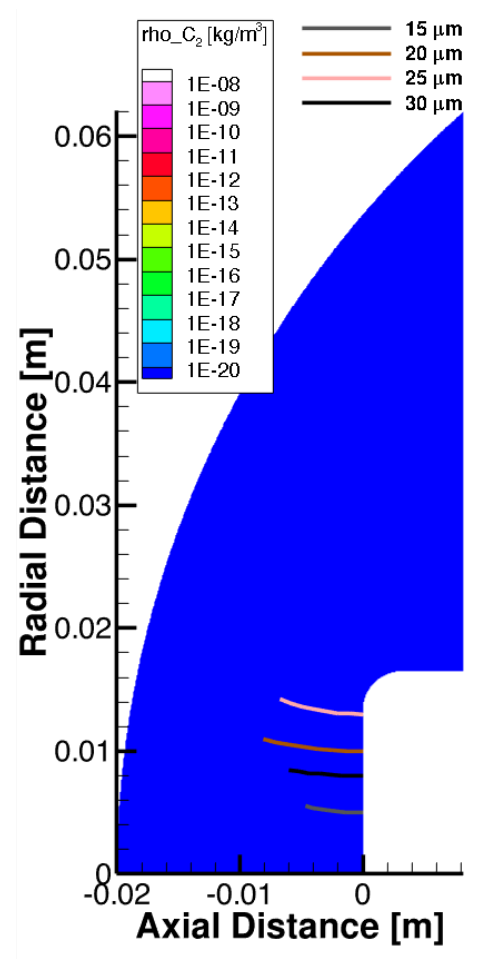

(e) $\mathrm{C}_{2}$ Density

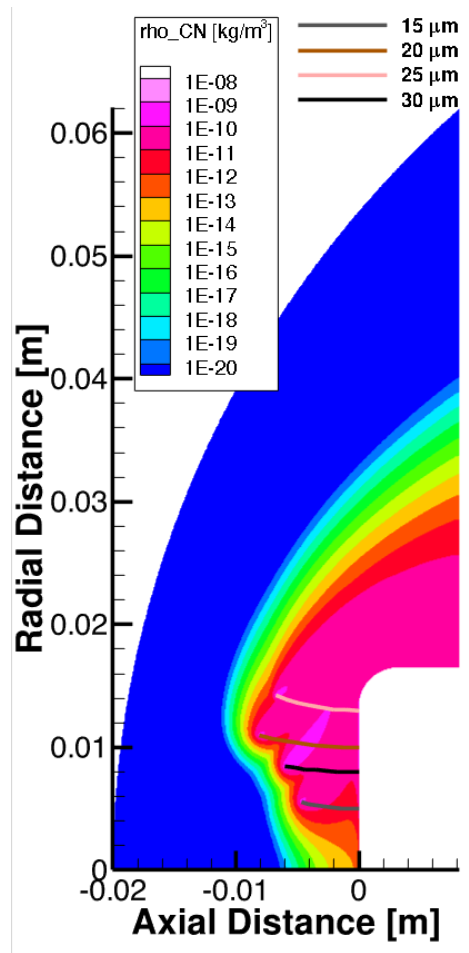

(c) CN Density

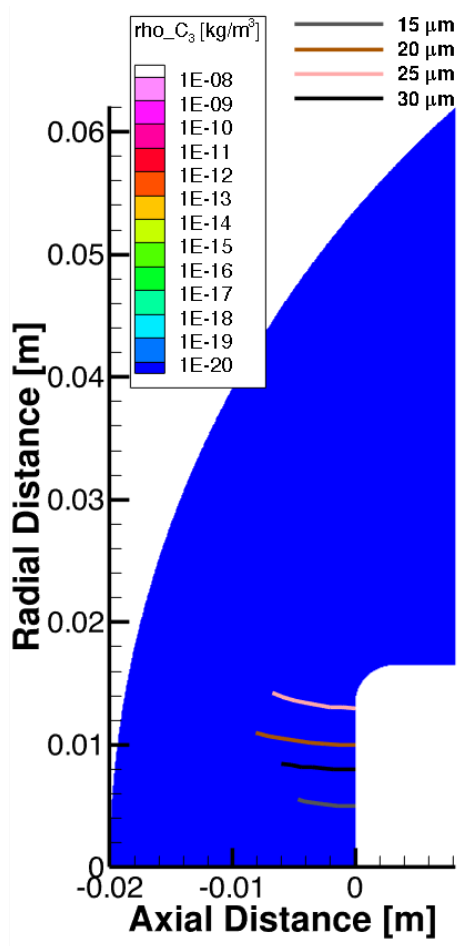

(f) $\mathrm{C}_{3}$ Density

Figure 16. Trajectories of the particles in temperature and carbon (-products) density profiles of the air flow field at 0.09 milli seconds 


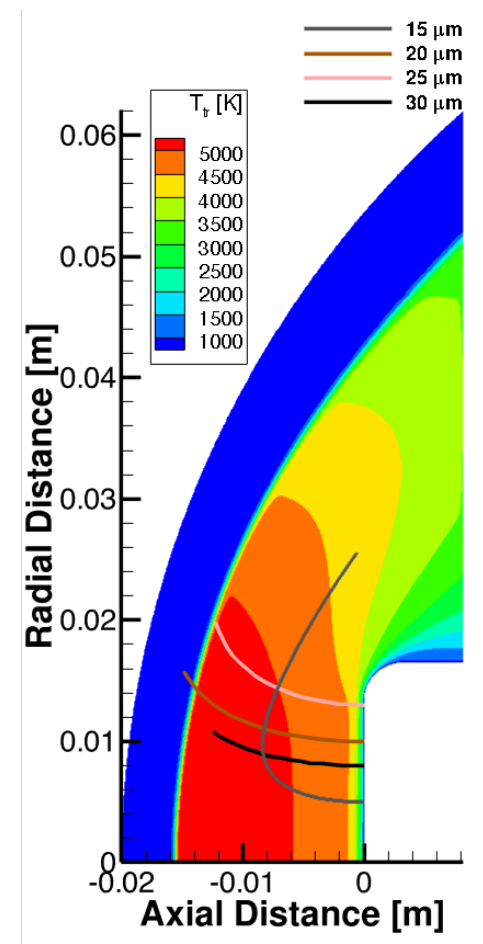

(a) Temperature

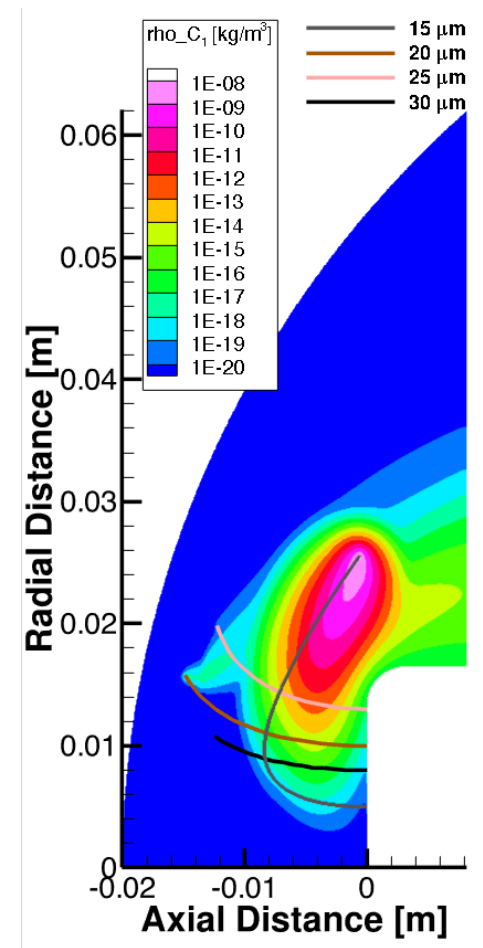

(d) $\mathrm{C}_{1}$ Density

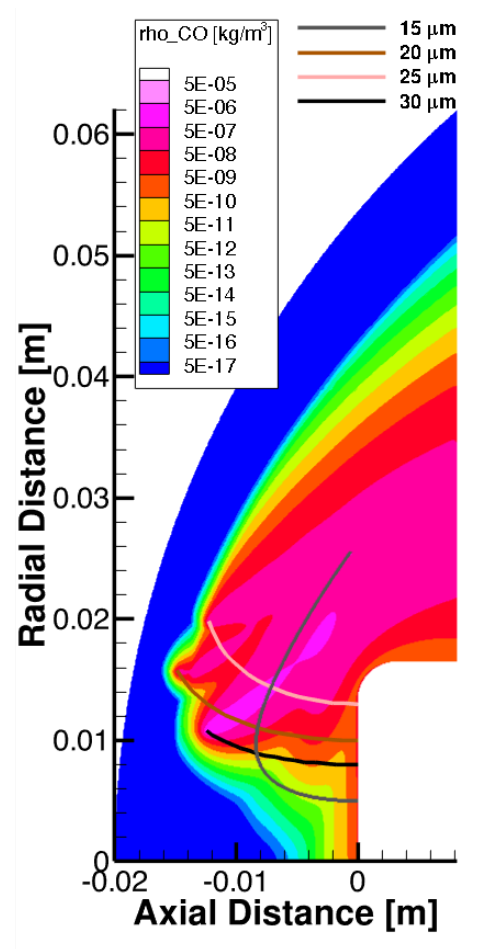

(b) CO Density

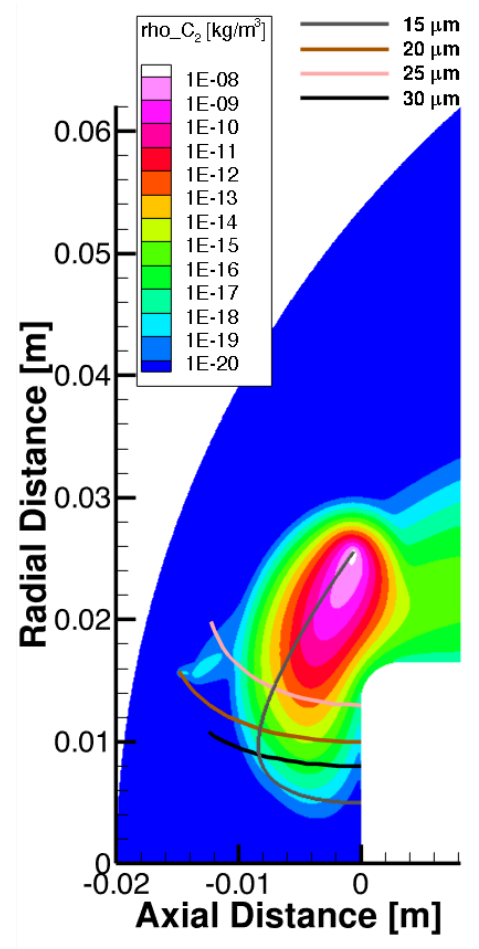

(e) $\mathrm{C}_{2}$ Density

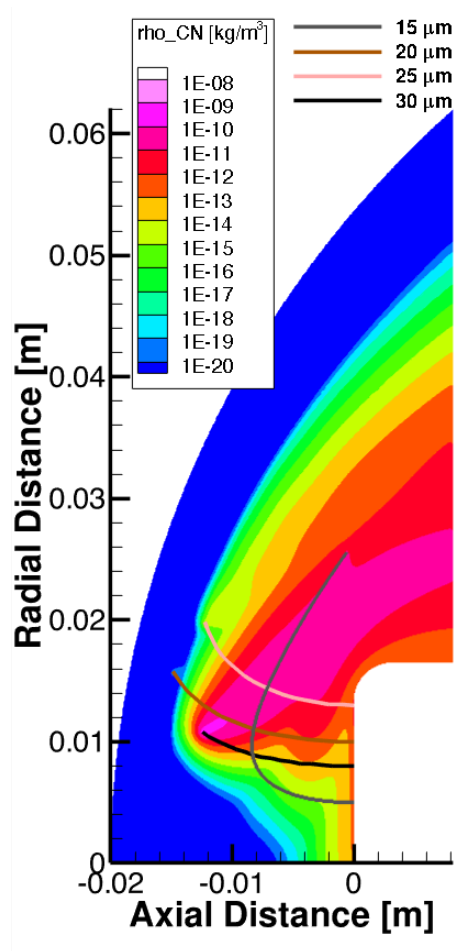

(c) CN Density

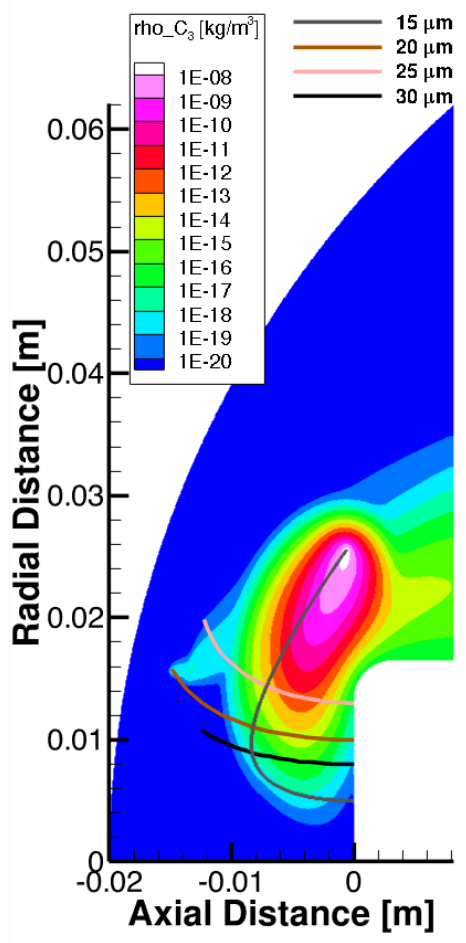

(f) $\mathrm{C}_{3}$ Density

Figure 17. Trajectories of the particles in temperature and carbon (-products) density profiles of the air flow field at 0.19 milli seconds 


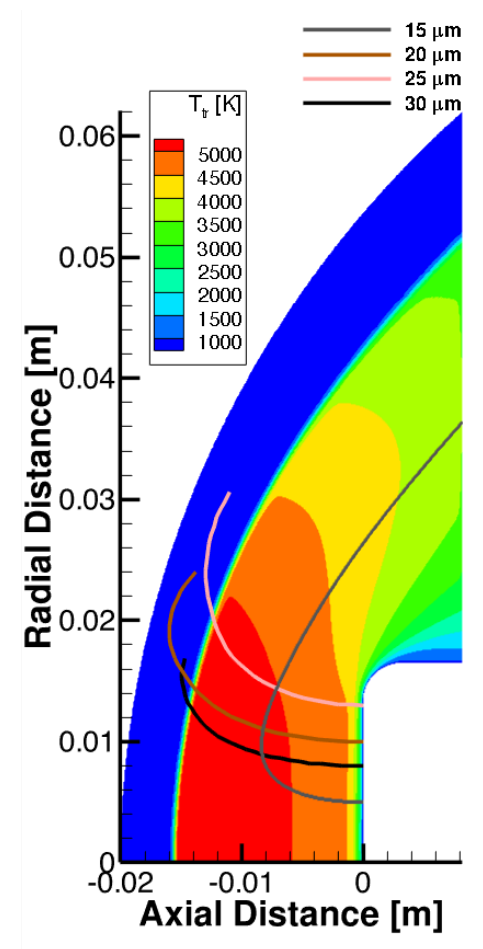

(a) Temperature

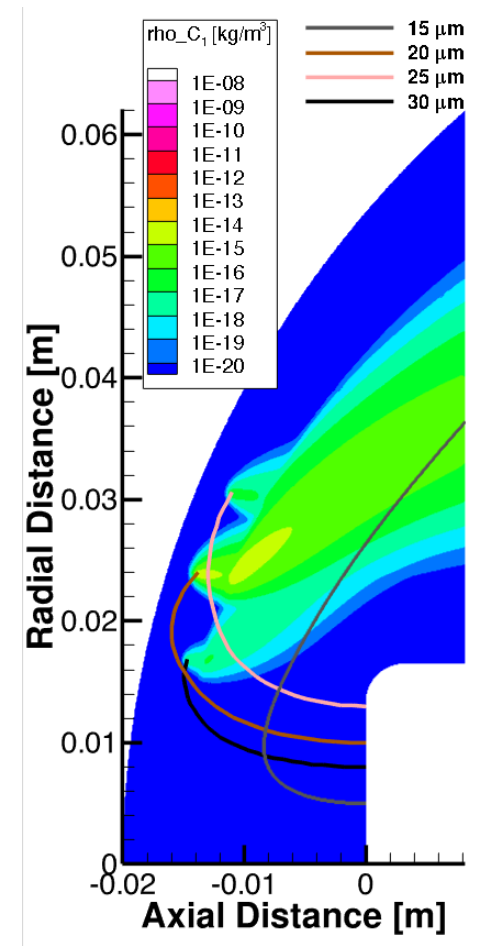

(d) $\mathrm{C}_{1}$ Density

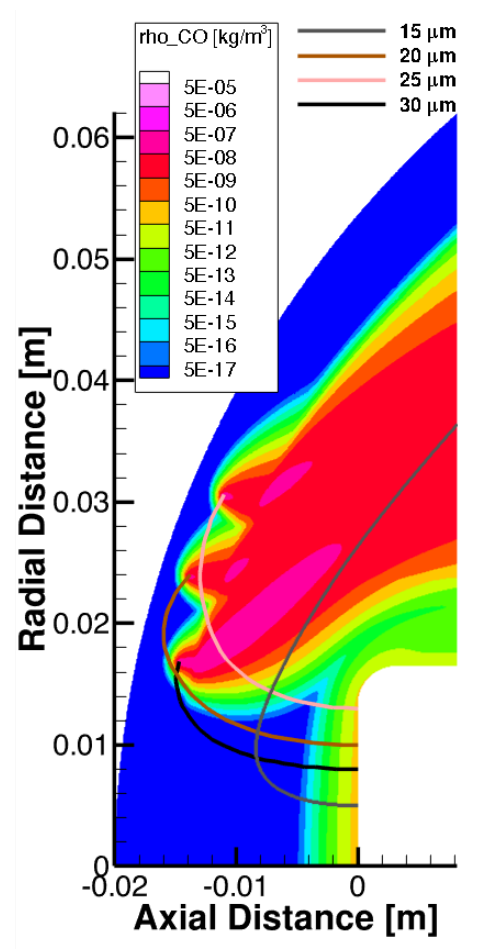

(b) CO Density

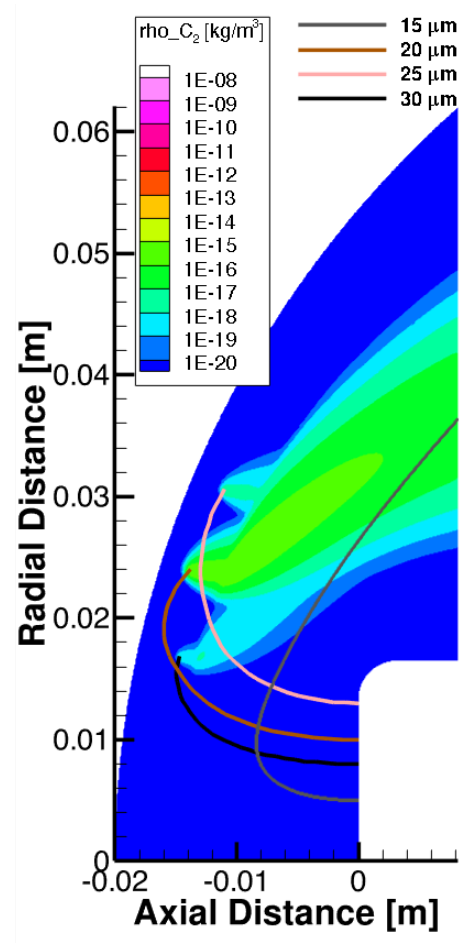

(e) $\mathrm{C}_{2}$ Density

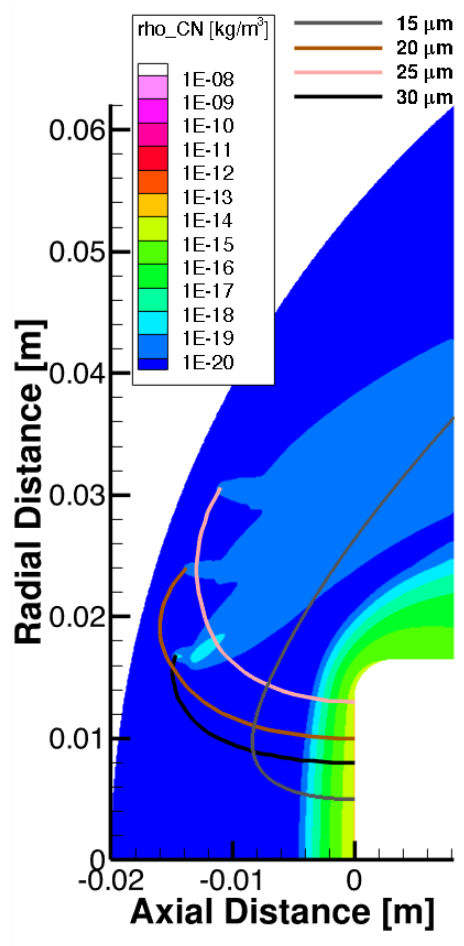

(c) CN Density

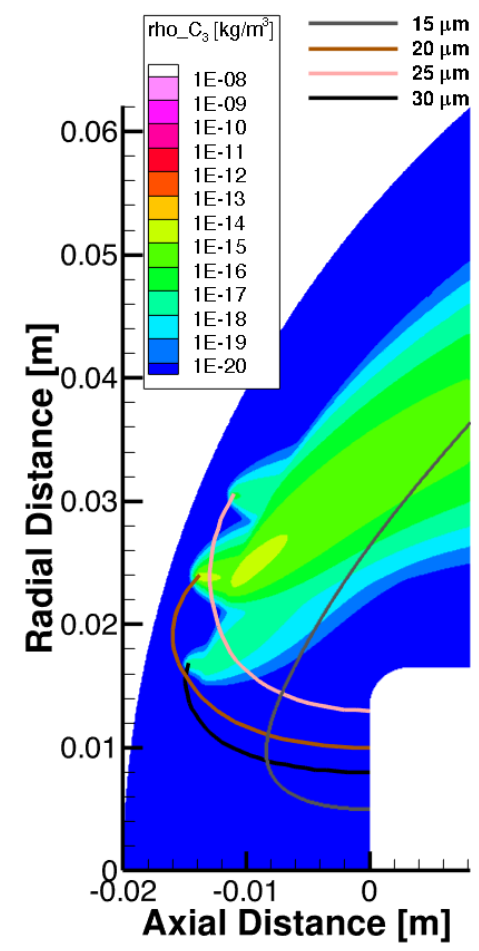

(f) $\mathrm{C}_{3}$ Density

Figure 18. Trajectories of the particles in temperature and carbon (-products) density profiles of the air flow field at 0.35 milli seconds 


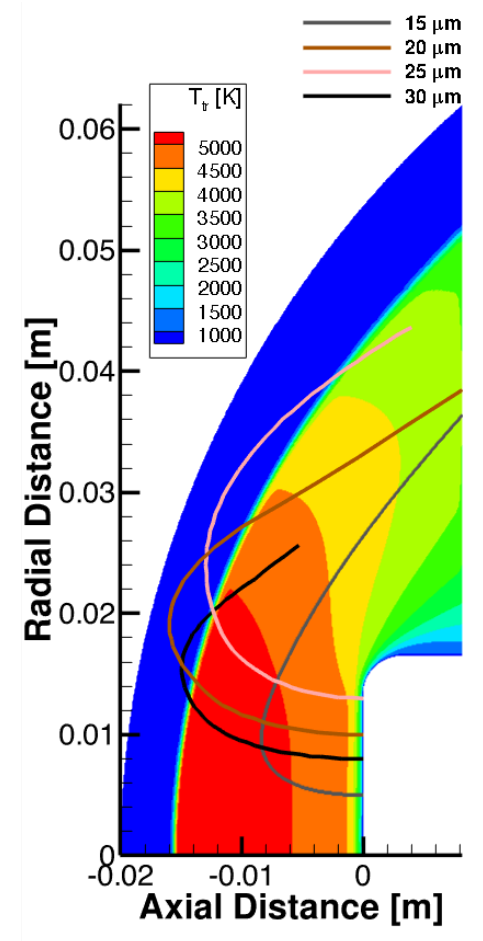

(a) Temperature

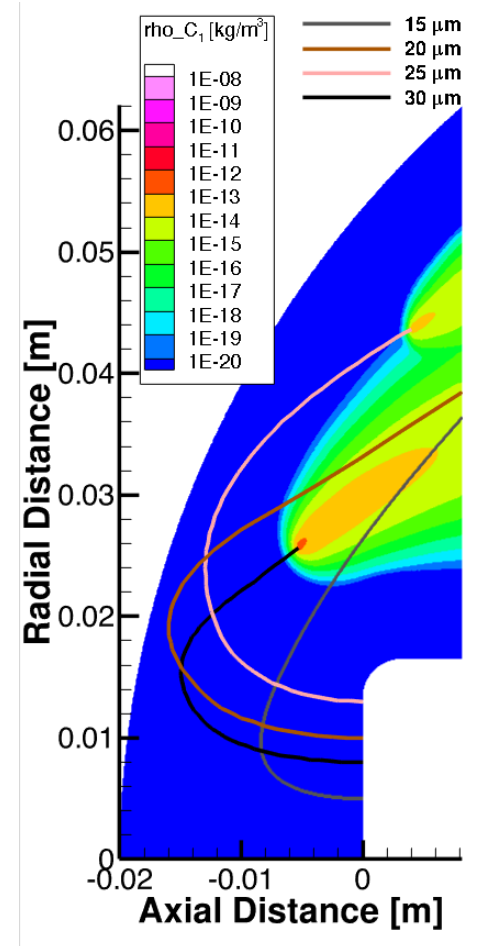

(d) $\mathrm{C}_{1}$ Density

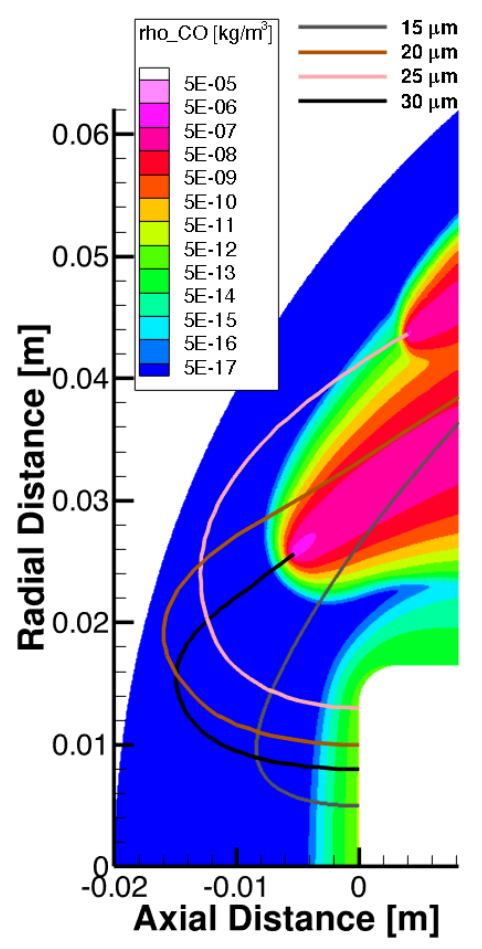

(b) CO Density

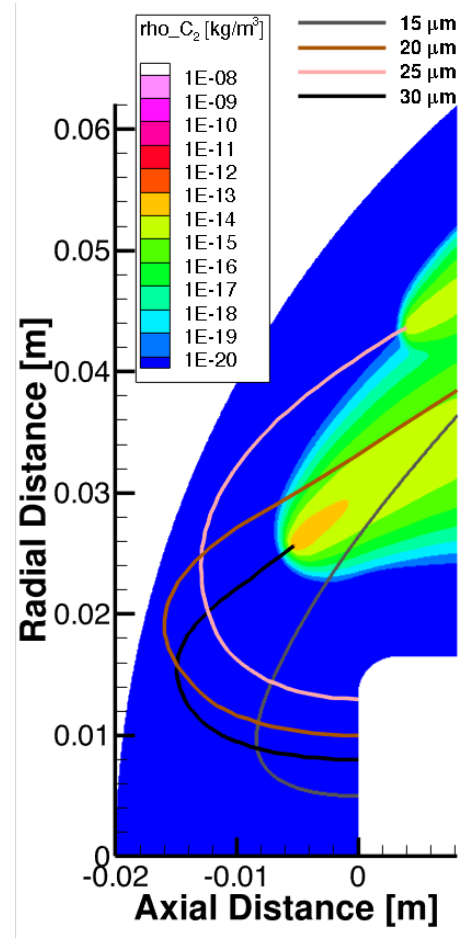

(e) $\mathrm{C}_{2}$ Density

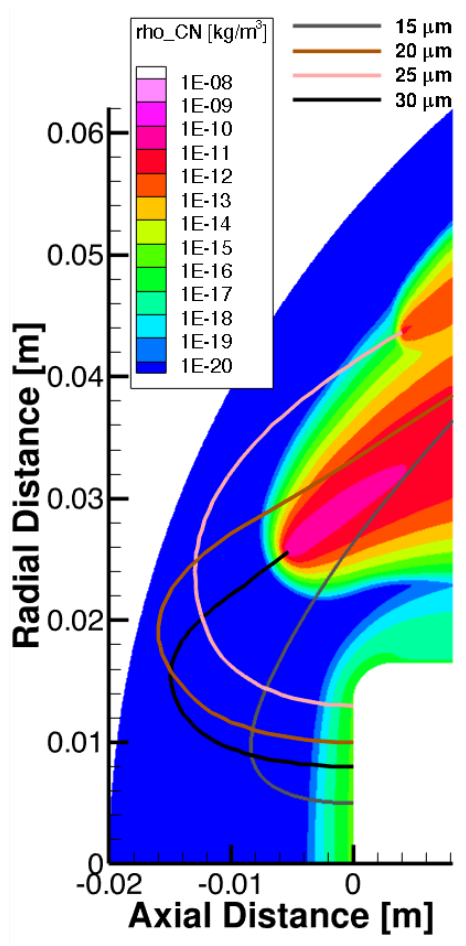

(c) CN Density

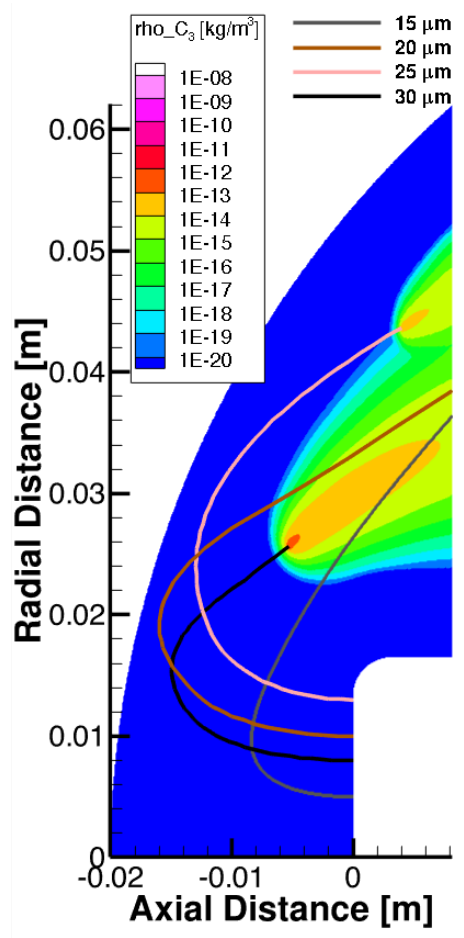

(f) $\mathrm{C}_{3}$ Density

Figure 19. Trajectories of the particles in temperature and carbon (-products) density profiles of the air flow field at 0.55 milli seconds 


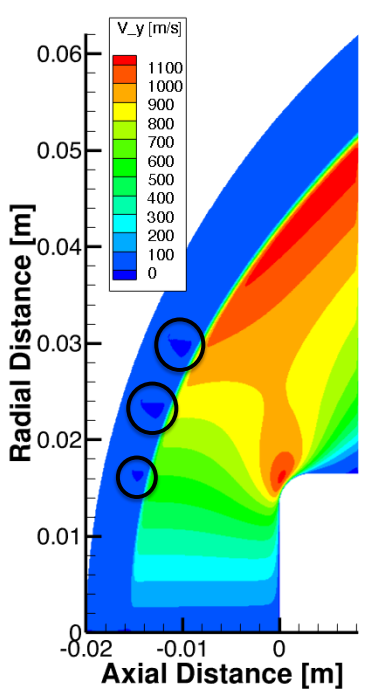

Figure 20. Velocity in $y$-direction of the air flow field at 0.35 milli seconds

the ejection. It is observed that the particle releases $\mathrm{CO}$ vapor throughout its entire travel whereas, CN vapor is hardly released ahead of the shock. The sublimation of the particle follows the same trend as it has in the argon flow field. The magnitude of concentration of $\mathrm{CO}$ vapor released is higher than the other vapors. However, it is noticed that the coupling results show a very small change in temperature of about $0.01 \mathrm{~K}$, and no change in flow field velocity.

The coupled simulation was also performed for multiple particles spalled in argon and air environments. The results for argon environment showed a pattern similar to that of single-particle simulation. The simulation for three particles show that the vapor released was convected and diffused over a larger area, and resulted in the change of temperature of $0.1 \mathrm{~K}$. Similarly, for air environment, the simulation was performed using four particles. It is noticed that the $\mathrm{CO}$ and $\mathrm{CN}$ vapor released diffused over a larger area, and a small concentration of these species remained close to the surface of the ablator.The particles also tend to sublimate in the post-shock area, and concentration of the sublimate species increased as the particles moved through the computational domain. The particle that did not reach the shock sublimates near the surface. These coupling results indicate the possible relationship between the presence of spalled particles and spectroscopic emissions, observed ahead of the shock. Also, the diffusive fluxes encompassed over larger areas provide a explanation for under-prediction of heat rates and temperature profiles in the downstream region.

\section{Acknowledgements}

Financial support for this work was provided by NASA Kentucky EPSCoR Award NNX10AV39A, and NASA award NNX13AN04A. 


\section{References}

${ }^{1}$ Wakefield, R. M. and Pitts, W. C., "Analysis of the Heat-Shield Experiment on the Pioneer-Venus Entry Probes," 15 th Thermophysics Conference, AIAA Paper 1980-1494, July 1980. doi:10.2514/6.1980-1494

${ }^{2}$ Balakrishnan, A. and Nicolet, W. E., "Galileo Probe Forebody Thermal Protection: Benchmark Heating Environment Calculations," 16th Thermophysics Conference, AIAA Paper 1981-1072, June 1981.

doi:10.2514/6.1981-1072

${ }^{3}$ Milos, F. S., "Galileo Probe Heat Shield Ablation Experiment," Journal of Spacecraft and Rockets, Vol. 34, No. 6, 1997, pp. $705-713$.

doi: $10.2514 / 2.3293$

${ }^{4}$ Moss, J. and Simmonds, A., "Galileo Probe Forebody Flowfield Predictions during Jupiter Entry," 3rd Joint Thermophysics, Fluids, Plasma and Heat Transfer Conference, AIAA Paper 1982-0874, 1982. doi:10.2514/6.1982-874

${ }^{5}$ Raiche, G. and Driver, D., "Shock Layer Optical Attenuation and Emission Spectroscopy Measurements During Arc Jet Testing with Ablating Models," 42nd AIAA Aerospace Sciences Meeting and Exhibit, AIAA Paper 2004-825, 2004. doi:10.2514/6.2004-825

${ }^{6}$ Yoshinaka, T., "Spallation Measurement at the Ablator Plasma Wind Tunnel Tests," Tech. Rep. NASDA-TMR-970006E, National Space Development Agency of Japan, Tokyo, February 1998.

${ }^{7}$ Kihara, H., Hatano, M., Nakiyama, N., Abe, K., and Nishida, M., "Preliminary Studies of Spallation Particles Ejected from an Ablator," Transactions of the Japan Society for Aeronautical and Space Sciences, Vol. 49, No. 164, 2006, pp. 65-70. doi:10.2322/tjsass. 49.65

${ }^{8}$ Davies, C. and Park, C., "Trajectories of solid particles spalled from a carbonaceous heat shield," 20th Aerospace Sciences Meeting, AIAA Paper 1982-200, 1982. doi:10.2514/6.1982-200

${ }^{9}$ Park, C., "Interaction of Spalled Particles with Shock Layer Flow," Journal of Thermophysics and Heat Transfer, Vol. 13, No. 4, 1999, pp. 441-449.

doi: $10.2514 / 2.6482$

${ }^{10}$ Nozawa, S., Kihara, H., and Abe, K., "Numerical Investigation of Spalled Particle Behavior Ejected from an Ablator Surface," Transactions of the Japan Society for Aeronautical and Space Sciences, Vol. 8, No. ists27, 2010, pp. Pe_9-Pe_14. doi:10.2322/tastj.8.Pe_9

${ }^{11}$ Pace, A., Ruffin, S., and Barnhardt, M., "A Coupled Approach for Predicting Radiation Attenuation in Particle-Laced Flows," 42nd AIAA Thermophysics Conference, AIAA Paper 2011-3771, 2011. doi:10.2514/6.2011-3771

${ }^{12}$ Wright, M. J., Candler, G. V., and Bose, D., "Data-Parallel Line Relaxation Method for the Navier-Stokes Equations," AIAA Journal, Vol. 36, No. 9, 1998, pp. 1603-1609. doi: $10.2514 / 2.586$

${ }^{13}$ Davuluri, R. S. C., Zhang, H., and Martin, A., "Numerical Study of Spallation Phenomenon in an Arc-Jet Environment," Journal of Thermophysics and Heat Transfer, 2015, pp. 1-10. doi:10.2514/1.T4586

14 Zhang, H.-B., Weng, H., and Martin, A., "Simulation of Flow-tube Oxidation on the Carbon Preform of PICA," 52nd AIAA Aerospace Sciences Meeting, AIAA Paper 2014-1209, National Harbor, MD, 13-17 January 2014. doi:10.2514/6.2014-1209

${ }^{15}$ Zhang, H.-B., High Temperature Flow Solver For Aerothermodynamics Problems, Ph.d. thesis, University of Kentucky, Lexington, Kentucky, August 2015.

${ }^{16}$ Davuluri, R. S. C., Modeling of Spallation Phenomenon in an arc-jet environment, Master thesis, University of Kentucky, Lexington, Kentucky, August 2015.

${ }^{17}$ Maclean, M., Marschall, J., and Driver, D. M., "Finite-Rate Surface Chemistry Model, II: Coupling to Viscous NavierStokes Code," 42nd AIAA Thermophysics Conference, AIAA Paper 2011-3784, June 2011. doi:10.2514/6.2011-3784

${ }^{18}$ Driver, D. M. and MacLean, M., "Improved predictions of PICA Recession in Arc Jet Shear Tests," 49th AIAA Aerospace Sciences Meeting, AIAA Paper 2011-141, January 2011. doi:10.2514/6.2011-141

${ }^{19}$ Baker, R. L., "Graphite Sublimation Chemistry Nonequilibrium Effects," AIAA Journal, Vol. 15, No. 10, October 1977, pp. 1391-1397.

doi:10.2514/3.60806

${ }^{20}$ Majid, A., Two phase flow solver for solid particles in hypersonic Martian entry flows, Ph.d. thesis, Universität Stuttgart, Stuttgart, Germany, 2011.

${ }^{21}$ Martin, A., Boyd, I., and Farbar, E., "Numerical modeling of the CN spectral emission of the Stardust re-entry vehicle," 42nd AIAA Thermophysics Conference, AIAA Paper 2011-3125, June 2011. doi:10.2514/6.2011-3125

${ }^{22}$ Martin, A. and Boyd, I. D., "Modeling of Heat Transfer Attenuation by Ablative Gases During the Stardust Reentry," Journal of Thermophysics and Heat Transfer, Vol. 29, No. 3, 2015, pp. 450-466.

doi:10.2514/1.T4202 